This article is a preprint, i.e. it is the author's version of the manuscript, prior to input from peer-reviewing. Hence there may be considerable differences compared to the final version of the article.

The final version of the article is published in:

Powder Technology 2014;256:75-86.

DOI: 10.1016/j.powtec.2014.01.085

The final version can be found here:

http://www.sciencedirect.com/science/article/pii/S0032591014001041 


\title{
Measuring attrition resistance of oxygen carrier particles for chemical looping combustion with a customized jet cup
}

\author{
Magnus Rydén*, Patrick Moldenhauer, Simon Lindqvist, Tobias Mattisson, Anders \\ Lyngfelt
}

\author{
Department of Energy and Environment \\ Chalmers University of Technology \\ SE-412 96, Gothenburg, Sweden
}

\begin{abstract}
A customized jet cup for measuring attrition resistance of oxygen carrier particles for chemical looping combustion has been constructed and used to evaluate 25 different material samples, all of which previously have been subject to continuous operation in chemical looping reactors at Chalmers University of Technology. The effect of continuous operation has been assessed by comparing attrition behaviour of fresh particles with that of used ones. It is concluded that the correlation between the jet cup tests and operational experience is robust, and that there is always considerable difference in attrition resistance between fresh and used particles of the same batch. Composite materials with $\mathrm{NiO}$ or $\mathrm{Fe}_{2} \mathrm{O}_{3}$ as active phase and $\mathrm{Al}_{2} \mathrm{O}_{3^{-}}, \mathrm{NiAl}_{2} \mathrm{O}_{4}$ - or $\mathrm{MgAl}_{2} \mathrm{O}_{4}$-based support and materials based on the $\mathrm{CaMnO}_{3-\delta}$ perovskite structure typically had high attrition resistance, which improved further following operation with fuel. Combined $\left(\mathrm{Fe}_{\mathrm{x}} \mathrm{Mn}_{1-\mathrm{x}}\right)_{2} \mathrm{O}_{3}$ oxides and all materials containing smaller or larger amounts of either $\mathrm{CuO}$ or $\mathrm{ZrO}_{2}$ experienced reduced attrition resistance during operation with fuel, and usually also had low attrition resistance to begin with. Fresh particles of the commonly used oxygen carrier ilmenite had reasonably high attrition resistance, while ilmenite that had been subject to chemical looping combustion of natural gas showed higher rate of attrition. No strong correlation between the commonly used crushing strength index and attrition resistance measured with jet cup could be established, but it was clear that particles with a crushing strength above $2 \mathrm{~N}$ were much more likely to have high attrition resistance compared to softer particles. As compared to crushing strength, the jet cup testing were better correlated to attrition in actual operation.
\end{abstract}

Keywords: Chemical looping combustion; Chemical looping reforming; Oxygen carrier particles; Attrition; Fluidization; Jet cup

\section{Introduction}

Chemical looping combustion (CLC) is an upcoming technology for $\mathrm{CO}_{2}$ capture currently under development. Chemical looping combustion requires solid particles with specific properties that are capable of enduring the extraordinary harsh conditions of fluidized-bed reactors. Development and selection of such particles is not trivial and considerable attention has been given to it in recent years. In order to find suitable materials we have adopted a scheme which is described in Figure 1. One of the objectives with this paper is to highlight the benefits of point $3 \mathrm{~d}$ in this scheme. 


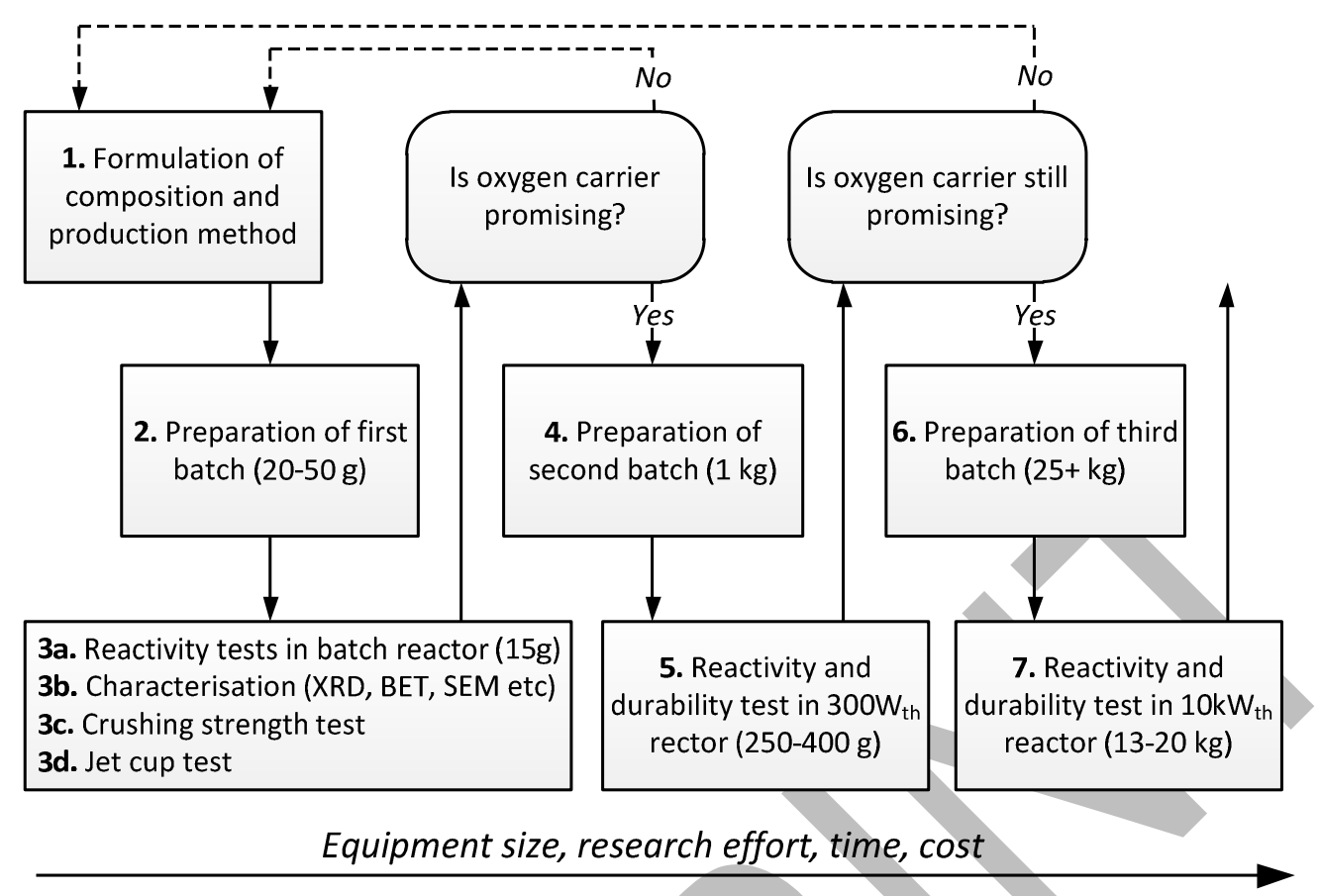

Figure 1) Chalmers oxygen carrier development scheme. This article concerns point $3 d$.

Generally speaking, it does not require large effort to be successful up to stage $3 \mathrm{~b}$ in the scheme described in Figure 1. It is possible to produce small samples of particles in any wellequipped laboratory with standard methods, and reactivity can be accurately measured in e.g. a simple fluidized bed quartz reactor. There are also numerous common but useful characterization techniques that require only very small amounts of solids (e.g. TGA, TPR, XRD, EDX, SEM, BET). Stages 4 to 7 on the other hand require more solids, larger and more complex reactor systems and a much more significant effort in terms of material, manpower, time and money. Therefore it is critical that the activities in stage 3 of the scheme are capable of producing reasonably adequate indications whether a certain oxygen carrier material is promising or not. Else there is a risk that a lot of time and effort is spent in producing and testing large batches of materials that are not useful.

As explained above, there are many good tools available for determining reactivity and chemical properties of small particle samples. In contrast, there is a lack of tools to characterize small samples of particles with respect to attrition behaviour in fluidized-bed reactors. The standard method is ASTM D5757 ${ }^{1}$ which involves vertical air jets of very high velocity and requires comparably large particle samples $(50 \mathrm{~g})$ and long operation time $(5 \mathrm{~h})$. This method is unsuitable for our specific needs. In recent years we have examined more than 400 different oxygen carrier materials in fluidized-bed batch reactors (stage $3 \mathrm{a}$ in Figure 1) using samples of $15 \mathrm{~g}$. As will be shown in this article, it is a very significant advantage if materials can be tested both before and after such laboratory testing. Thus the ASTM D5757 method cannot be used since we have less than $50 \mathrm{~g}$ available of used samples. Also $5 \mathrm{~h}$ of operation time was considered too extensive for a method intended for material screening.

Crushing strength tests have been used extensively by us and others since 10 years ${ }^{2,3}$, and while useful it is not a very reliable indicator on behaviour in fluidized-bed reactor. Moreover, 
crushing strength tests cannot easily be made on particles that have been examined in the batch reactor because of their small size. Reproducible crushing strength tests typically require particles in the size range $180-250 \mu \mathrm{m}$ or larger, while batch experiments normally need to be performed with smaller particles in the size range 125-180 $\mu \mathrm{m}$. Thus, no satisfactory comparison can be made of crushing strength (point $3 c$ in Figure 1) before and after fluidization and testing in the batch reactor (point 3a in Figure 1).

The purpose of this paper is to assess whether measuring resistance towards mechanical attrition with a customized jet cup (point $3 \mathrm{~d}$ in Figure 1) could be a meaningful indicator to assist in the development of durable oxygen carrier particles for chemical looping combustion. A jet cup is a device designed to simulate the effects of grid jet attrition and cyclone attrition, typically considered to be the two main contributors to mechanical attrition in circulating fluidized-bed combustion. Jet cup testing is not a standardized method and exists in different iterations, see for example Cocco et al. ${ }^{4}$, Zhao et al. ${ }^{5}$ and Weeks \& Dumbill $^{6}$. Most commonly the method is used to measure attrition resistance of bed material for fluid catalytic cracking.

The device described in this paper is similar to PSRI's improved cylindrical jet cup ${ }^{2}$, but the size of the equipment has been scaled down in order to be suitable for samples as small as $5 \mathrm{~g}$. Using smaller samples may result in larger measurement error compared to using larger samples, see Cocco et al. ${ }^{4}$. But for our purpose using larger samples is not an option since we want to use the jet cup at stage 3 of our development scheme where we typically conduct experiments with $15 \mathrm{~g}$ batches. Thus by choosing a sample size of $5 \mathrm{~g}$ attrition resistance can be examined both for fresh and used samples.

The purpose of this work is not to develop a method capable of safe predictions. That would be unrealistic considering the complexity in the process of particle-size reduction, the very large number of completely different materials which are currently being examined as oxygen carriers for chemical looping combustion, and the absence of chemical reactions during testing at room temperature. Neither is it our intention to propose a new industrial standard for material characterization. Instead, the aim is to introduce a tool that potentially could improve the early selection process during material development in schemes similar to ours, Figure 1.

In this study, the proposed method has been used to examine a number of oxygen carrier particles which already have been subject to continuous operation (stage 5 or stage 7 in Figure 1). The results have been compared with operational experience in order to determine if there is a meaningful correlation between attrition resistances measured with jet cup and performance in fluidized-bed reactor under operating conditions. A comparison is also made to results from testing of crushing strength.

\section{Background}

\subsection{Chemical looping combustion}

Chemical looping combustion is an innovative method to utilize fuels in which the fuel is oxidized using two separate reactor vessels, one air reactor (AR) and one fuel reactor (FR). A solid oxygen-carrier, typically a transition metal oxide $\left(\mathrm{MeO}_{\mathrm{x}}\right)$, performs the task of transporting oxygen to the fuel and circulates continuously between the two reactors. In the 
fuel reactor it is reduced by the fuel, which in turn is oxidized to $\mathrm{CO}_{2}$ and $\mathrm{H}_{2} \mathrm{O}$. In the air reactor it is oxidized to its initial state with $\mathrm{O}_{2}$ from air. The net energy released in the reactor system is the same as in ordinary combustion, and the operating temperature of each reactor is expected to be in the range of $800-1050^{\circ} \mathrm{C}$. A schematic description of chemical looping combustion can be found in Figure 2.

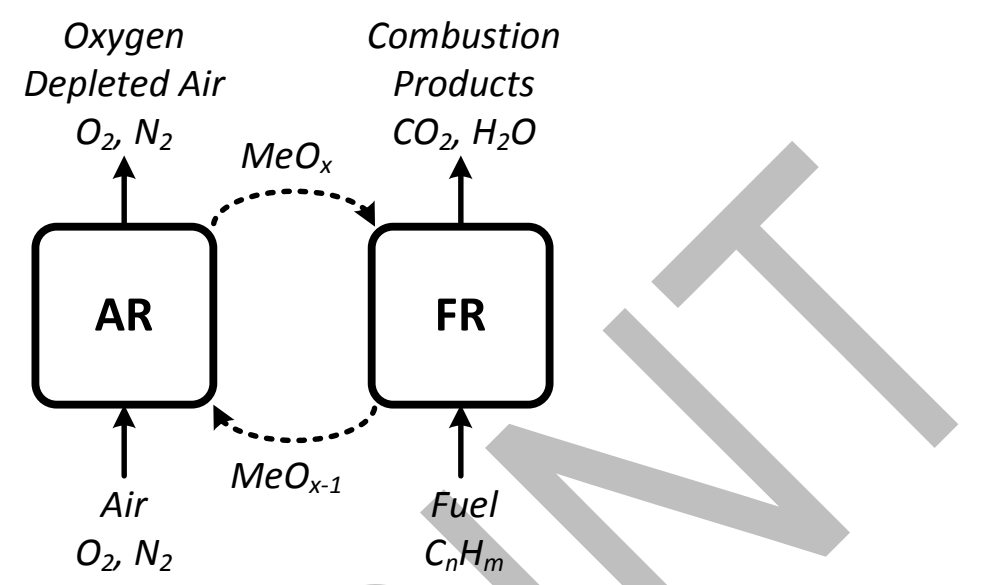

Figure 2) Schematic description of chemical looping combustion.

Compared to conventional combustion, chemical looping combustion would provide some intriguing benefits. Most importantly, fuel is never mixed with $\mathrm{N}_{2}$ from the combustion air. Hence condensation of the steam produced in the fuel reactor is sufficient to obtain almost pure $\mathrm{CO}_{2}$. There is no inherent energy penalty or cost associated with chemical looping combustion, so oxidation of carbon-containing fuels with this method could be considered an ideal technology for carbon capture and storage (CCS). An overview showing how carbon capture and storage can contribute to reduced emissions of the greenhouse gas $\mathrm{CO}_{2}$ to the atmosphere can be found in IPCC's special report about the subject ${ }^{7}$.

Chemical-loping combustion can be realized in several ways, but the most commonly proposed design utilize fluidized beds in a similar way as a conventional circulating fluidizedbed boiler (CFB), with the difference that the bed material used in such facilities would be replaced with an active oxygen carrier material. This design has proven to be feasible but experience from operation of several prototype reactors also show that some oxygen carrier materials are subject to severe attrition. It is clear that better understanding of this phenomenon is needed in order to facilitate design and scale-up of chemical looping processes.

The basic ideas behind chemical looping combustion can be traced back to the middle of the past century to work by Lewis \& Gilliland et al. ${ }^{8,9}$. The stated purposes of these early process proposals were production of synthesis gas $\left(\mathrm{CO}+\mathrm{H}_{2}\right)$ or high purity $\mathrm{CO}_{2}$. Other early work includes a study from 1983 by Richter and Knoche ${ }^{10}$, who suggested a fuel oxidation reaction scheme involving two intermediate reactions with a metal oxide as oxygen carrier in order to reduce irreversibility compared to ordinary combustion. Ishida et al. ${ }^{11}$ coined the term chemical looping combustion in 1987 while putting forward similar ideas as Richter and Knoche. Chemical looping combustion as a method to separate $\mathrm{CO}_{2}$ during fuel oxidation was 
proposed a few years later by Ishida and $\mathrm{Jin}^{12}$, soon to be followed by a basic design for a circulating fluidized-bed reactor by Lyngfelt et al. ${ }^{13}$ in 2001. From that moment, research about chemical looping combustion has been growing rapidly and in numerous directions. Work is now performed by several research groups using a wide range of operating principles, reactor designs and oxygen carrier materials. Lyngfelt ${ }^{14}$ recently reported that more than 700 oxygen carrier materials have been examined and the technology has been successfully demonstrated in sustained operation for in total more than 4000 hours in reactors in the size range 0.3-140 kW using different types of oxygen carriers based on oxides of the metals $\mathrm{Ni}$, $\mathrm{Co}, \mathrm{Fe}, \mathrm{Cu}$ and $\mathrm{Mn}$. It is not possible to provide a complete overview of the topic here so the interested reader is referred to the recent review article by Adanez et al. ${ }^{15}$ or Lyngfelt ${ }^{16}$, or to the book by $\operatorname{Fan}^{17}$.

\subsection{Particle attrition in fluidized beds}

Particle attrition is a widely spread phenomenon, common not only in industrial handling of particles and powders but also in nature. A young beach may contain mostly broken rocks or angular stones. If subject to nature's forces (waves, winds etc.) for a certain time period the stones will eventually be turned to rounded pebbles, which eventually will be turned to sand. This transformation of stones to sand is due to different attrition phenomena. If for example a large force is applied onto a particle, it might break in two, a mechanism typically referred to as fragmentation. A smaller force may not be able to break the particle but could give rise to a small number of coarse fragments instead (fines, dust, etc.), a mechanism typically referred to as abrasion. The daughter particles formed will be subject to further attrition. A description of the fundamentals of particle attrition is provided by Bemrose \& Bridgwater ${ }^{18}$. A summary of basic variables known to influence particle attrition is listed in Table 1.

\begin{tabular}{|c|c|}
\hline Properties of particles & Properties of environment \\
\hline $\begin{array}{l}\text { Size } \\
\text { Shape } \\
\text { Surface } \\
\text { Porosity } \\
\text { Hardness } \\
\text { Cracks }\end{array}$ & $\begin{array}{l}\text { Time } \\
\text { Velocity } \\
\text { Pressure } \\
\text { Shear } \\
\text { Temperature }\end{array}$ \\
\hline
\end{tabular}

Table 1. Some variables affecting attrition of particles.

A fluidized bed is a particularly unforgiving environment in which particles are subject to a greatly accelerated rate of attrition compared to the natural environment, see Werther \& Reppenhagen ${ }^{19}$. One of the most important sources of attrition in a fluidized bed are the grid jets in the bottom of the bed which often must be operated with very high gas velocities. Circulating fluidized beds also typically involve cyclones for separation of gas and solids which give rise to considerable attrition as the particles impact the cyclone wall at high speed. Other presumably less important sources for attrition in fluidized beds are collision between particles when bubbling in the bed or splashing in the freeboard above the bed.

During chemical looping combustion in a fluidized bed, oxygen carrier particles will not only be subject to mechanical forces but also to high temperatures and chemical reactions. One important application that shares similarities with chemical looping combustion in this 
respect is circulating fluidized-bed combustion with in-situ sulphur capture, in which the limestone particles are subject to mechanical and thermal forces as well as to chemical reactions. Scala et al. ${ }^{20-24}$ have classified attrition phenomena in fluidized beds for this process on the basis of the breakage mechanism and the size of generated fragments. Primary fragmentation occurs directly upon injection of particles in the bed as a consequence of thermal stress and internal gas pressure, the latter occurs due to calcination of $\mathrm{CaCO}_{3}$ to $\mathrm{CaO}$ and gaseous $\mathrm{CO}_{2}$. Secondary fragmentation takes place in the dense bed or in the splashing zone and results in the generation of either coarse or fine fragments. Secondary fragmentation that generates coarser fragments occurs mainly as a consequence of mechanical stress. This type of fragmentation may onset as a result of high-velocity collisions against targets, which can be reactor walls, internals or other particles. High-velocity impact are experienced by the particles mainly close to the grid jets near the bottom of the bed and are closely related to the design of the gas distributor. The exit region of the riser and the cyclone are other potential locations of impact damage of sorbent particles. Secondary fragmentation that generates finer fragments (abrasion) happens due to surface wear as the emulsion phase of the fluidized bed is sheared by the passage of bubbles.

Other industrial applications that share some similarities with chemical looping combustion is the Dupont process for production of maleic anhydride in a circulating fluidized bed, see Contractor et al. ${ }^{25}$, and to some extent fluid catalytic cracking of oil, see Boerefijn et al. ${ }^{26}$. It seems reasonable to believe that experience from large-scale operation of these kinds of processes can provide some general ideas about challenges involved for scaling up and further developing chemical looping combustion.

\subsection{Particle attrition during chemical looping combustion}

Most chemical looping research has been focusing on the use of synthetic monometallic oxides of transition metals such as $\mathrm{Fe}_{2} \mathrm{O}_{3}, \mathrm{NiO}, \mathrm{CuO}$ or $\mathrm{Mn}_{3} \mathrm{O}_{4}$ as oxygen carrier. Minerals, ores and waste materials from industrial activities have also been examined, as have more complex combined oxides. There is a lack of studies examining particle attrition during chemical looping combustion though. One study with comprehensive methodology has been conducted by Brown et al. $^{27}$, who examined iron ore and a synthetic CuO-based oxygen carrier using a range of different methods. The study indicated that the attrition resistance of the iron ore was reduced substantially when subject to repeated reduction and oxidation, while the CuO-based particles did not suffer from this effect.

A few other studies report perceived attrition behaviour as complementary information to other results, see for example Gayán et al. ${ }^{28}$ who examined NiO-based particles by over 120 cycles of oxidation and reduction in a bubbling fluidized bed and reported attrition as loss of fines per cycle. A number of authors have reported attrition behaviour during continuous chemical looping combustion in different kinds of reactor systems, typically by determining changes in particle size distribution or by weighing the amounts of fine material generated during operation, see for example Lyngfelt \& Thunman $^{29}$, Linderholm et al. ${ }^{30}$, Berguerand et al. $^{31}$ and Adanez et al. ${ }^{32}$.

The studies outlined above do not provide much information about the relative relevance of different attrition mechanisms, i.e. primary fragmentation, secondary fragmentation and abrasion. Table 2 gives an overview of different sources of attrition which we consider as 
potentially important during chemical looping combustion in circulating fluidized beds. Table 2 is based mainly on the work about with in-situ sulphur capture by limestone of Scala et $\mathrm{al}^{20-}$ 24 .

\begin{tabular}{llll}
\hline Factor & Description & Type & Region of occurrence \\
\hline Grid Jets & High velocity gas jets & Mechanical & Grid region \\
Cyclone & High velocity impact & Mechanical & Cyclone wall \\
Bubbling & Low velocity impact & Mechanical & Fluidized bed \\
Splashing & Low velocity impact & Mechanical & Freeboard \\
Thermal shock & Induced stress & Property change & Fluidized bed \\
Internal gas pressure & Explosion, sublimation & Property change & Fluidized bed \\
Chemical reaction & Change in crystal lattice & Property change & Fluidized bed \\
\hline
\end{tabular}

Table 2. Potential sources of particle attrition during chemical looping combustion in circulating fluidized beds.

At present, it is not possible to conclude for sure which of the factors suggested in Table 2 are most relevant for chemical looping combustion. But it seems reasonable to believe that the high velocity grid jets and the cyclones are the most important contributors among the mechanical forces, and that chemical reactions are the most important ones among the material property factors. This could differ considerably between different oxygen carrier materials and reactor designs though.

\section{Experimental}

\subsection{Jet cup rig}

For this study a customized test rig based on the jet cup method ${ }^{4,5,6}$ was designed and constructed. While not a standardized method this design allows for small samples and short test periods. The resulting apparatus consists of a $39 \mathrm{~mm}$ high conical cup with an inner diameter of $13 \mathrm{~mm}$ in the bottom and $25 \mathrm{~mm}$ in the top. The reason for choosing a conical design rather than a cylindrical is recent research by Cocco et $\mathrm{al}^{4}{ }^{4}$, which indicates that a conical design improves mixing and movement of solids during testing greatly. A nozzle with an inner diameter of $1.5 \mathrm{~mm}$ is located at the bottom of the cup, and tangentially in relation to the cup wall. During operation, air is added with a velocity of approximately $100 \mathrm{~m} / \mathrm{s}$ through the inlet nozzle, creating a vortex of particles swirling upwards through the cup. The cup design is intended to induce accelerated attrition with mechanisms similar to grid jets (due to the high gas velocity in the nozzle) and cyclones (due to the cone shaped particle vortex). A schematic description of the cup can be found in Figure 3.

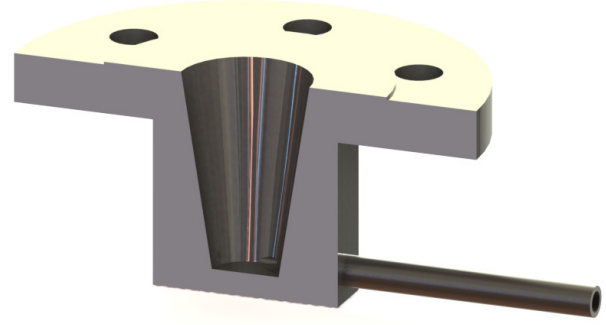


Figure 3) Geometry of the conical jet cup used in this study.

The cup is located at the bottom of a $634 \mathrm{~mm}$ high gravitational particle-gas separator, basically a cone with a maximum diameter of $216 \mathrm{~mm}$. Due to the increasing cross-section area, the gas velocity in the settling chamber is less than $1 / 20000$ compared to the inlet. The low gas velocity in the upper part of the gravitational separator allows elutriated particles to fall back into the cup, while generated fines are allowed to exit. A particle filter with a $0.01 \mu \mathrm{m}$ filter element is located at the top of the device.

Static electricity causes particles to adhere to the inner walls if the apparatus. In order to minimize this issue a humidifier was connected to the air inlet. It consists of a plastic bottle where the air bubbles though a water column of a certain height, typically $240 \mathrm{~mm}$. The apparatus was operated at room temperature and close to atmospheric pressure. A schematic description of the test rig can be found in Figure 4.
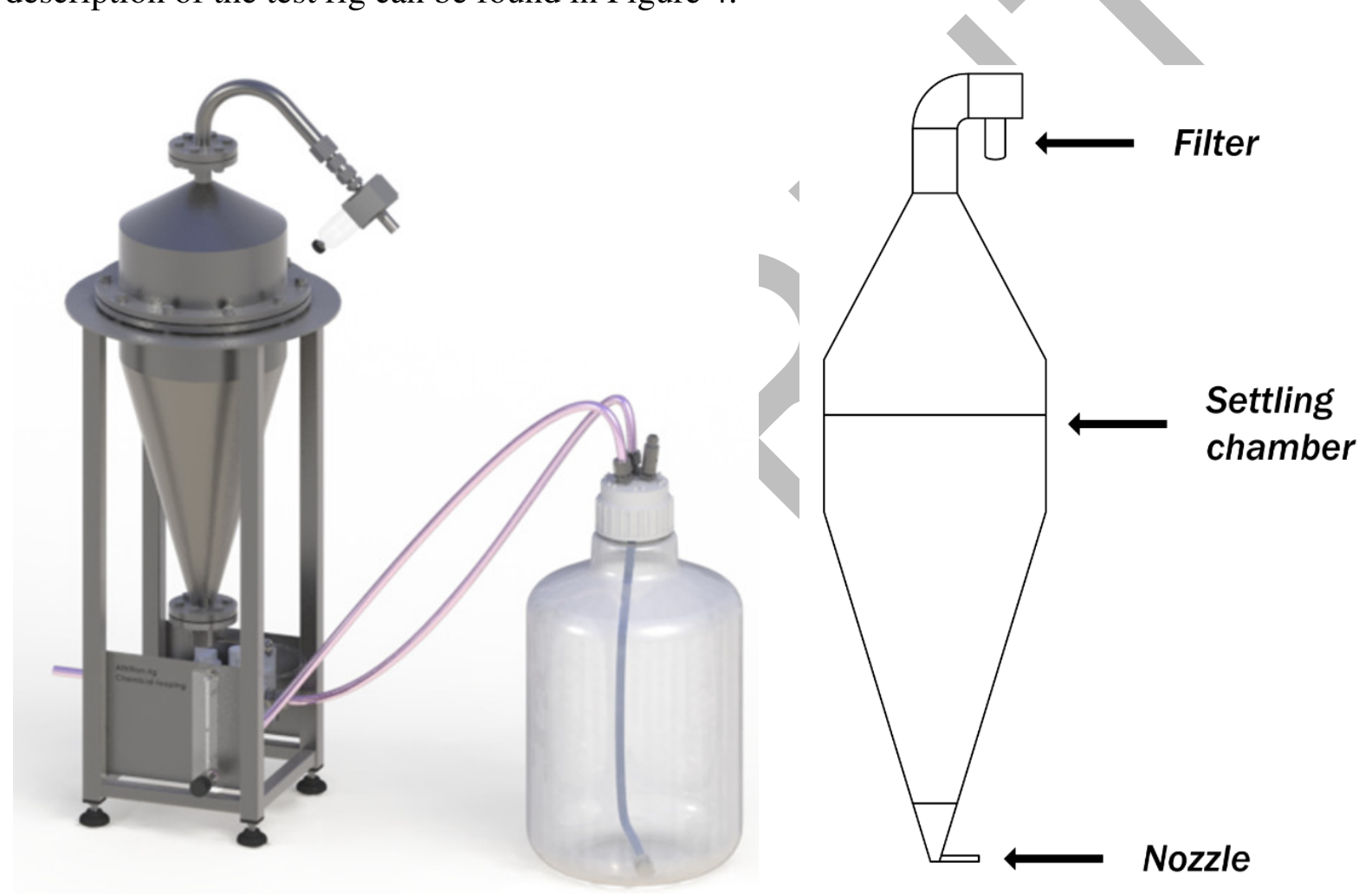

Figure 4) Schematic description of the test rig used in this study.

\subsection{Oxygen carrier materials}

The oxygen carriers used for this work have all been previously examined during continuous chemical looping experiments in circulating fluidized-bed reactors at Chalmers University of Technology. The idea was to compare qualitative and quantitative experience from work with continuously operating chemical looping combustors operating with fuel and high temperatures, with quantitative results obtained with the jet cup as well as with crushing strength measurements. The experiments involve 25 different materials, some of which have shown excellent performance and some of which have shown poor performance. The particles differ greatly in chemical composition and also in the way they have been manufactured. A summary of the oxygen carrier particles examined with phase composition, production 
method and references to papers describing their manufacturing and detailed characteristics can be found in Table 3 .

\begin{tabular}{|c|c|c|c|c|}
\hline Oxygen Carrier & Composition (wt\%) & Production method & Calcination & References \\
\hline $\mathrm{CaMn}_{0.9} \mathrm{Mg}_{0.1} \mathrm{O}_{3-\delta}$ & $\mathrm{CaMn}_{0.9} \mathrm{Mg}_{0.1} \mathrm{O}_{3-\delta}$ & Spray drying & $4 \mathrm{~h}$ at $1300^{\circ} \mathrm{C}$ & 33 \\
\hline $\mathrm{CaMn}_{0.875} \mathrm{Ti}_{0.125} \mathrm{O}_{3}$ & $\mathrm{CaMn}_{0.875} \mathrm{Ti}_{0.125} \mathrm{O}_{3-\delta}$ & Freeze granulation & $3 \mathrm{~h}$ at $1200^{\circ} \mathrm{C}$ & 34 \\
\hline F3-1100 & $66.8 / 32.2(\mathrm{Fe} / \mathrm{Mn})_{2} \mathrm{O}_{3}$ & Spray drying & $4 \mathrm{~h}$ at $1100^{\circ} \mathrm{C}$ & 35 \\
\hline F7-950 & $20.7 / 79.3(\mathrm{Fe} / \mathrm{Mn})_{2} \mathrm{O}_{3}$ & Spray drying & $4 \mathrm{~h}$ at $950^{\circ} \mathrm{C}$ & unpublished \\
\hline M4MZ-1150 & $40 / 60 \mathrm{Mn}_{3} \mathrm{O}_{4} / \mathrm{Mg}-\mathrm{ZrO}_{2}$ & Freeze granulation & $6 \mathrm{~h}$ at $1150^{\circ} \mathrm{C}$ & 36 \\
\hline M4MZ-1200 & $40 / 60 \mathrm{Mn}_{3} \mathrm{O}_{4} / \mathrm{Mg}-\mathrm{ZrO}_{2}$ & Spray drying & $4 \mathrm{~h}$ at $1200^{\circ} \mathrm{C}$ & 37 \\
\hline C4Z-950 & $40 / 60 \mathrm{CuO} / \mathrm{ZrO}_{2}$ & Spray drying & $4 \mathrm{~h}$ at $950^{\circ} \mathrm{C}$ & unpublished \\
\hline $\mathrm{C} 4 \mathrm{Ce}-950$ & $40 / 60 \mathrm{CuO} / \mathrm{CeO}_{2}$ & Spray drying & & unpublished \\
\hline C2Z-1050 & $20 / 80 \mathrm{CuO} / \mathrm{ZrO}_{2}$ & Spray drying & & 37 \\
\hline F6A-1100 & $60 / 40 \mathrm{Fe}_{2} \mathrm{O}_{3} / \mathrm{Al}_{2} \mathrm{O}_{3}$ & Freeze granulation & $6 \mathrm{~h}$ at $1100^{\circ} \mathrm{C}$ & 38 \\
\hline Grace- $-\mathrm{Fe}_{2} \mathrm{O}_{3}$ & $60 / 40 \mathrm{Fe}_{2} \mathrm{O}_{3} / \mathrm{MgAl}_{2} \mathrm{O}_{4}$ & Freeze granulation & $6 \mathrm{~h}$ at $1100^{\circ} \mathrm{C}$ & 39 \\
\hline F6AM-1150 & $60 / 40 \mathrm{Fe}_{2} \mathrm{O}_{3} / \mathrm{MgAl}_{2} \mathrm{O}_{4}$ & Freeze granulation & $6 \mathrm{~h}$ at $1150^{\circ} \mathrm{C}$ & 40 \\
\hline F6MZ-1100 & $60 / 40 \mathrm{Fe}_{2} \mathrm{O}_{3} / \mathrm{Mg}-\mathrm{ZrO}_{2}$ & Freeze granulation & $6 \mathrm{~h}$ at $1100^{\circ} \mathrm{C}$ & unpublished \\
\hline Ilmenite & $\approx \mathrm{FeTiO}_{\mathrm{x}}$ & Crushing, beneficiati & none & $31,41,42,43$ \\
\hline Iron oxide scales & $\approx \mathrm{Fe}_{2} \mathrm{O}_{3}$ & Crushing & $24 \mathrm{~h}$ at $950^{\circ} \mathrm{C}$ & 42 \\
\hline Manganese ore ${ }^{\S}$ & $\approx \mathrm{Mn}_{2} \mathrm{O}_{3}$ & & none & 35 \\
\hline Manganese ore ${ }^{\S}$ & $\approx \mathrm{Mn}_{2} \mathrm{O}_{3}$ & Crushing & none & 44 \\
\hline N4MZ-1400 & $60 / 40 \mathrm{NiO} / \mathrm{Mg}-\mathrm{ZrO}_{2}$ & Freeze granulation & $6 \mathrm{~h}$ at $1400^{\circ} \mathrm{C}$ & 45,46 \\
\hline N2AM-1400 & $20 / 80 \mathrm{NiO} / \mathrm{MgAl}_{2} \mathrm{O}_{4}$ & Freeze granulation & $6 \mathrm{~h}$ at $1400^{\circ} \mathrm{C}$ & 47 \\
\hline $\mathrm{N} 21-\gamma-\mathrm{Al}_{2} \mathrm{O}_{3}$ & $21 / 79 \mathrm{NiO} / \gamma-\mathrm{Al}_{2} \mathrm{O}_{3}$ & Wet impregnation & $1 \mathrm{~h}$ at $950^{\circ} \mathrm{C}$ & 47 \\
\hline $\mathrm{N} 18-\alpha-\mathrm{Al}_{2} \mathrm{O}_{3}$ & $18 / 82 \mathrm{NiO} / \alpha-\mathrm{Al}_{2} \mathrm{O}_{3}$ & Wet impregnation & 1h at $950^{\circ} \mathrm{C}$ & 47,48 \\
\hline N-IFP & $60 / 40 \mathrm{NiO} / \mathrm{NiAl}_{2} \mathrm{O}_{4}$ & Spin flash drying & $\mathrm{n} / \mathrm{a}$ & 49 \\
\hline N-Vito & $40 / 60 \mathrm{NiO} / \mathrm{NiAl}_{2} \mathrm{O}_{4}$ & Spray drying & $4 \mathrm{~h}$ at $1450^{\circ} \mathrm{C}$ & 30,48 \\
\hline N-Vito-Mg & $40 / 60 \mathrm{NiO} / \mathrm{MgAl}_{2} \mathrm{O}_{4}$ & Spray drying & $4 \mathrm{~h}$ at $1400^{\circ} \mathrm{C}$ & 30,48 \\
\hline Grace-NiO & $40 / 60 \mathrm{NiO} / \mathrm{NiAl}_{2} \mathrm{O}_{4}$ & Freeze granulation & $6 \mathrm{~h}$ at $1600^{\circ} \mathrm{C}$ & 39,29 \\
\hline
\end{tabular}

${ }^{\S}$ Eastern European, ${ }^{\S \S}$ Brazilian

Table 3. Oxygen carrier particles examined with composition, production method and references to experiments describing continuous operation with said material composition.

The physical characteristics of fresh and used particles can be found in Table 4. "Used" in this case means that the particles have been operated continuously at hot conditions with fuel.

Reported crushing strength was measured as the strength needed to fracture particles of the size 180-250 $\mu \mathrm{m}$ using a digital force gauge. The numbers provided are average for a number of measurements, normally 30. No numbers have been presented for crushing strength on used particles. The reason is that most often it was not possible to measure crushing strength on used samples with this methodology in a satisfactory way. Prior to continuous operation particles are sieved either to $90-212 \mu \mathrm{m}$ or to $125-180 \mu \mathrm{m}$. During continuous operation a lot of materials also experience densification or fragmentation, both of which results in reduced particle diameter. Because of this, used samples typically contains no particles in the size range $212-250 \mu \mathrm{m}$ and quite few in the larger range $180-250 \mu \mathrm{m}$, which is the size range 
deemed as suitable to obtain reproducible results with the force gauge. Since crushing strength is dependent on particle size, measuring on particles with smaller size than what we use for fresh particles would introduce a systematic error.

Density was measured simply by weighing a certain volume of particles in a glass cylinder, so the numbers presented in Table 4 are for bulk density. The operational history of the particles specifically examined in the jet cup has also been included in the Table.

\begin{tabular}{|c|c|c|c|c|}
\hline Oxygen Carrier & $\begin{array}{l}\mathbf{C S}_{\text {fresh }} \\
(\mathbf{N})\end{array}$ & $\begin{array}{l}\rho_{\text {fresh }} \\
\left(\mathbf{k g} / \mathbf{m}^{3}\right)\end{array}$ & $\begin{array}{l}\rho_{\text {used }} \\
\left(\mathbf{k g} / \mathbf{m}^{3}\right)\end{array}$ & Operation history \\
\hline $\mathrm{CaMn}_{0.9} \mathrm{Mg}_{0.1} \mathrm{O}_{3-\delta}$ & 2.6 & 1800 & 2090 & $10 \mathrm{~kW}_{\text {th }} 55 \mathrm{~h} \mathrm{CLC} / \mathrm{CLOU} \mathrm{NG}^{33}$ \\
\hline $\mathrm{CaMn}_{0.875} \mathrm{Ti}_{0.125} \mathrm{O}_{3}$ & 1.2 & 1100 & 1200 & $300 \mathrm{~W}_{\text {th }} 70 \mathrm{~h} \mathrm{CLC} / \mathrm{CLOU} \mathrm{NG}^{34}$ \\
\hline F3-1100 & 2.7 & 1500 & 530 & $300 \mathrm{~W}_{\text {th }} 10 \mathrm{~h} \mathrm{CLC} / \mathrm{CLOU} \mathrm{NG} \mathrm{NG}^{35}$ \\
\hline F7-950 & 0.7 & 970 & 460 & $300 \mathrm{~W}_{\text {th }} 10 \mathrm{~h}$ CLC/CLOU SG \\
\hline M4MZ-1150 & 0.7 & 1400 & 1100 & $300 \mathrm{~W}_{\text {th }} 25 \mathrm{~h} \mathrm{CLC} \mathrm{NG}$ \\
\hline M4MZ-1200 & $\mathrm{n} / \mathrm{a}$ & 1310 & 940 & $300 \mathrm{~W}_{\text {th }} 17 \mathrm{~h}$ CLC kerosene $\mathrm{e}^{37}$ \\
\hline C4Z-950 & 3.4 & 2040 & 1590 & $300 \mathrm{~W}_{\mathrm{th}} 4 \mathrm{~h}$ CLOU/CLC NG \\
\hline C4Ce-950 & 1.0 & 1950 & 1900 & $300 \mathrm{~W}_{\mathrm{th}} 9 \mathrm{~h}$ CLOU/CLC NG \\
\hline $\mathrm{C} 2 \mathrm{Z}-1050$ & 0.4 & 1540 & 1680 & $300 \mathrm{~W}_{\text {th }} 45 \mathrm{~h}$ CLC kerosene $\mathrm{s}^{37}$ \\
\hline F6A-1100 & 1.3 & 1200 & 1600 & $300 \mathrm{~W}_{\mathrm{th}} 40 \mathrm{~h} \mathrm{CLC} \mathrm{NG/SG}{ }^{38}$ \\
\hline Grace- $-\mathrm{Fe}_{2} \mathrm{O}_{3}$ & 0.7 & 1050 & 2130 & $10 \mathrm{~kW}_{\text {th }} 17 \mathrm{~h} \mathrm{CLC} \mathrm{NG}^{39}$ \\
\hline F6AM-1150 & 0.6 & 1000 & 1600 & $300 \mathrm{~W}_{\text {th }} 13 \mathrm{~h}$ CLC/SIR SG ${ }^{40}$ \\
\hline F6MZ-1100 & 1.1 & 1200 & 1150 & $300 \mathrm{~W}_{\text {th }} 5 \mathrm{~h} \mathrm{CLC} \mathrm{NG}$ \\
\hline Ilmenite & 3.7 & 2400 & 1280 & $300 \mathrm{~W}_{\text {th }} 83 \mathrm{~h} \mathrm{CLC} \mathrm{NG}^{41}$ \\
\hline Iron oxide scales & 8.3 & 2400 & 1400 & $300 \mathrm{~W}_{\text {th }} 37 \mathrm{~h} \mathrm{CLC} \mathrm{SG}^{42}$ \\
\hline Manganese ore ${ }^{\S}$ & $\mathrm{n} / \mathrm{a}$ & 1730 & 1090 & $300 \mathrm{~W}_{\text {th }} 9 \mathrm{~h} \mathrm{CLOU/CLC} \mathrm{NG} \mathrm{NG}^{35}$ \\
\hline Manganese ore ${ }^{\S \S}$ & 1.3 & 1725 & 1740 & $10 \mathrm{~kW}_{\text {th }} 10 \mathrm{~h} \mathrm{CLC} \mathrm{coal}^{44}$ \\
\hline N4MZ-1400 & & 2750 & 2480 & $300 \mathrm{~W}_{\text {th }} 40 \mathrm{~h} \mathrm{CLR} / \mathrm{CLC} \mathrm{NG}^{45}$ \\
\hline N2AM-1400 & 2.5 & 2760 & 2760 & $300 \mathrm{~W}_{\text {th }} 59 \mathrm{~h} \mathrm{CLR} / \mathrm{CLC} \mathrm{NG}^{47}$ \\
\hline $\mathrm{N} 21-\gamma-\mathrm{Al}_{2} \mathrm{O}_{3}$ & 2.6 & 1530 & 2230 & $300 \mathrm{~W}_{\text {th }} 42 \mathrm{~h} \mathrm{CLR} / \mathrm{CLC} \mathrm{NG}^{47}$ \\
\hline $\mathrm{N} 18-\alpha-\mathrm{Al}_{2} \mathrm{O}_{3}$ & 4.1 & 2100 & 2290 & 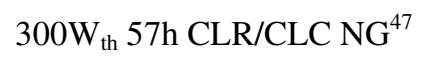 \\
\hline ИГО & 5.1 & 2770 & 2250 & $10 \mathrm{~kW}_{\text {th }} 160 \mathrm{~h} \mathrm{CLC} \mathrm{NG}^{49}$ \\
\hline N-Vito & 2.3 & 2410 & $2500^{\S \S}$ & $10 \mathrm{~kW}_{\text {th }} 1016 \mathrm{~h} \mathrm{CLC} \mathrm{NG}^{30}$ \\
\hline $\mathrm{N}-$ Vito-Mg & 2.3 & 2180 & $2500^{\S \S \S}$ & $10 \mathrm{~kW}_{\text {th }} 611 \mathrm{~h} \mathrm{CLC} \mathrm{NG}{ }^{30}$ \\
\hline Grace-NiO & 2.5 & 2550 & 2100 & $10 \mathrm{~kW}_{\text {th }} 100 \mathrm{~h} \mathrm{CLC} \mathrm{NG}^{29}$ \\
\hline
\end{tabular}

Table 4. Physical properties and operation history of particle samples examined. $C L C=$ Chemical looping Combustion, CLOU=Chemical looping with Oxygen Uncoupling, $C L R=$ Chemical looping reforming, SIR=Steam-Iron Reaction, $N G=$ Natural Gas, $S G=$ Synthesis gas with the composition $50 / 50 \mathrm{CO} / \mathrm{H}_{2}$.

In Table 4 it can be seen that the different particles have experienced very different operational conditions, ranging from a few hours of operation in a small $300 \mathrm{~W}_{\text {th }}$ reactor up to $1016 \mathrm{~h}$ of operation in a larger $10 \mathrm{~kW}_{\text {th }}$ reactor. Some materials have been examined in different reactors and for different kinds of experiments. In those cases, only one used sample has been examined in the jet cup rig. The operational history of that examined sample can be 
found in the column "operational history" in Table 4. The reported time of operation in this column refers to active operation with fuel addition and chemical reactions taking place. Each material has been fluidized in hot and cold condition without reaction for much longer time periods. When available a reference has been provided in which it is described in more detail what each sample has experienced. In some cases this has not been possible though since some experimental campaigns are unpublished, or still waiting to be published.

As can be seen in Table 4, different samples have been subject to different kinds of operation and fuels. Most materials have been exposed to gaseous fuels such as natural gas or syngas, but liquid and solid fuels have been used in a number of studies as well. The different reactors could also be expected to induce attrition by different mechanisms. The $10 \mathrm{~kW}_{\text {th }}$ units involve grid jets and cyclones operating with considerable gas velocities, while the $300 \mathrm{~W}_{\text {th }}$ units operate with lower gas velocities. This makes interpretation of the jet cup experiments quite complex as will be further elaborated below. For detailed description of each chemical looping reactor, the reader is referred to the references given in Table 4.

\subsection{Methodology}

Prior to examination, samples of fresh and used particles were prepared by sieving to 125 $180 \mu \mathrm{m}$. In a few cases not enough of material was available in that particular size range, and a larger size span of 90-212 $\mu \mathrm{m}$ was used instead. This is not believed to have influenced the results to any larger degree but has been indicated in Table 5 below anyway.

Prior to the experiments the filter was removed and weighed. The cup was dismantled and filled with $5.0 \mathrm{~g}$ of particles. Both parts were then reattached to the apparatus. An air flow of $10 \mathrm{l} / \mathrm{min}$ was applied to the nozzle for $1 \mathrm{~h}$, which corresponds to an air jet velocity of $\approx 94 \mathrm{~m} / \mathrm{s}$. The air flow was stopped so that the filter could be removed and weighed every 10 minutes. Although minor amounts of dust may stick to the cone walls in the upper part of the particlegas separator, the weight of the filter during each stop proved to give a good indication of how much fines were produced during each 10 minute period.

The term fines in this case is used to refer to particles which are capable of passing the settling chamber of a jet cup setup described in section 3.1, using the methodology outlined above. It can be assumed to correspond to particles with terminal velocity below the superficial gas velocity in the settling chamber which is $0.0047 \mathrm{~m} / \mathrm{s}$. In most cases this should equal particles smaller than $\approx 10 \mu \mathrm{m}$, but the exact cut-off diameter for each material is a function of density and geometry.

After the test period, the apparatus was disassembled and the particles remaining in the cup were collected. The parts were then cleaned and a mass balance was made in order to verify that only minor amounts of material were lost. Typically, 0.1-2.0 wt $\%$ of the particles was missing, corresponding to 5-100 mg. These particles could have been lost during handling or got stuck inside the settling chamber, for example in flanges. In general, the mass balance for particles with low attrition rate was much better compared to particles with high attrition rate. These numbers were considered as acceptable, and it is not reasonable that lost particles could have influenced the conclusions of the study.

For most of the materials the physical appearance and size distribution of the sample (fresh and used) was determined by taking several pictures of each sample with a light microscope. The images were then processed using a computer program calculating the size of each 
individual particle in each picture, approximated as the minimum Feret diameter. Thus a descriptive albeit somewhat idealized size distribution could be obtained based on measurements on hundreds of individual particles. Many materials were also examined by scanning electron microscopy (SEM), which possibly could provide information about structural abnormities such as for example cracks in the surface of the particles.

In addition to attrition measurements with the jet cup rig, the crushing strength of most of the materials was also measured, or had been measured in previous studies. As was explained in the introduction crushing strength has been used by several research groups as an indication whether different kinds of oxygen carrier particles can be expected to be resistant towards attrition a fluidized bed, see for example Adanez et al. ${ }^{32}$, Wang et al. ${ }^{50}$, Li et al. ${ }^{51}$ and Ishida et al. $^{52}$. However, it is not really well established whether crushing strength provides a fair estimation of the resistance of materials towards attrition in a fluidized bed environment. Hence it is of interest to compare the results of such measurements with those provided using a jet cup.

\subsection{Data evaluation}

As could be expected, different particles showed quite different behaviour in the jet cup. Most of the used particles tested and also some fresh ones showed linear attrition as a function of time, see Figure 5. Such behaviour suggests steady attrition mainly by abrasion.

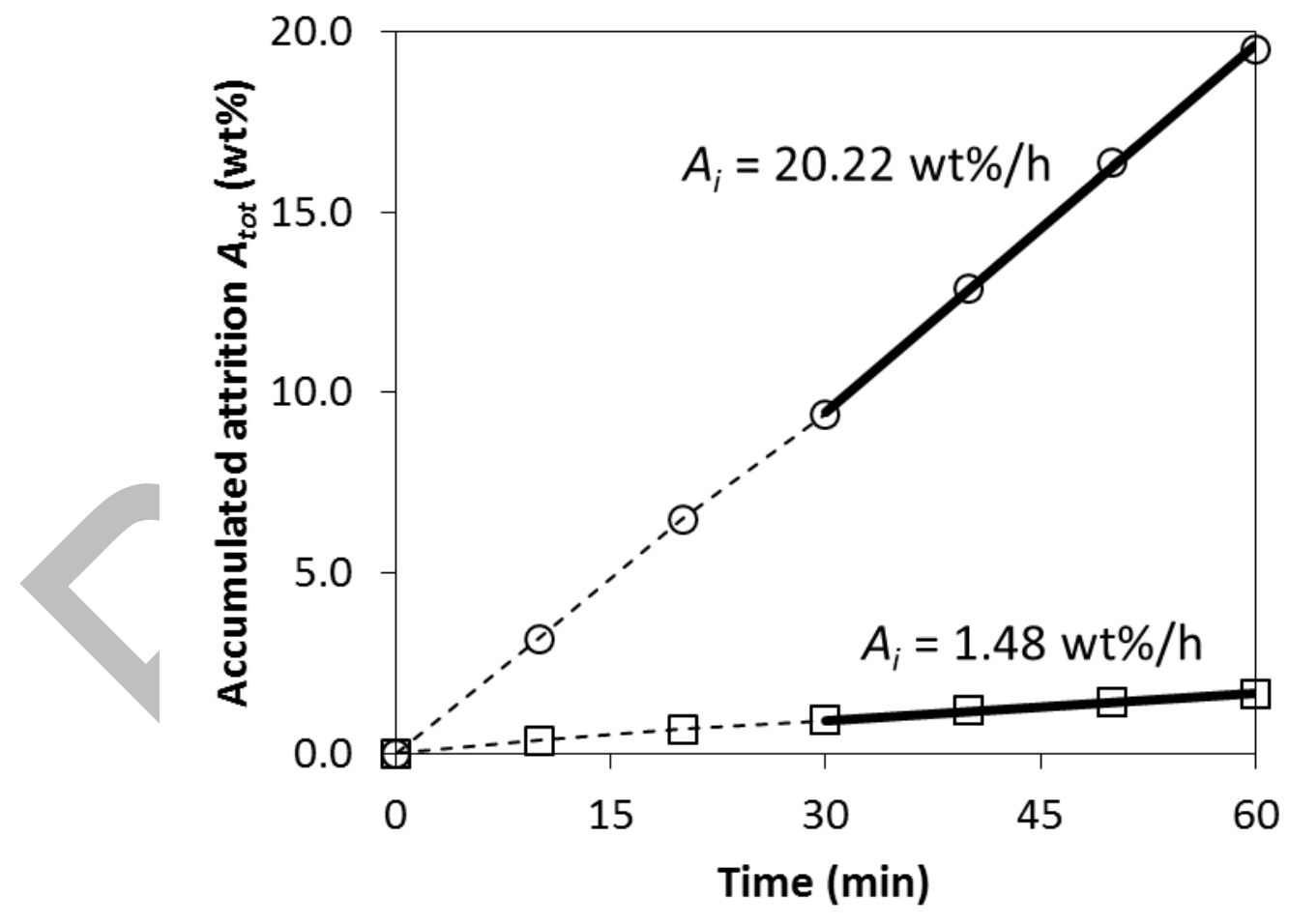

Figure 5) Attrition curve of fresh C2Z-1050(○) and fresh Iron Oxide Scales( $\square)$, showing linear attrition. Although practically constant during the test period the attrition index $A_{i}$ is defined as the slope of the curve for the last 30 min of the test.

While several of the fresh materials showed linear attrition the majority showed logarithmic attrition, such as in Figure 6. 


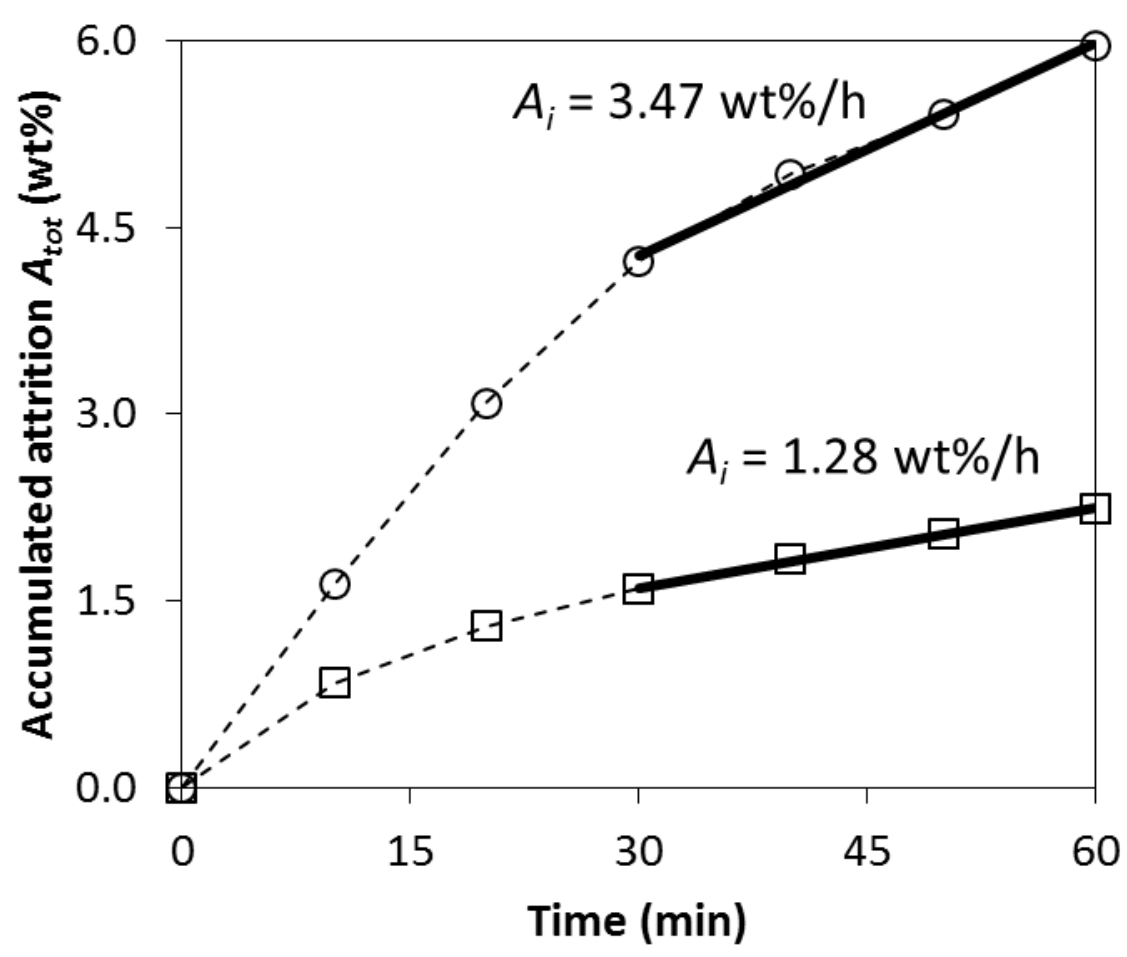

Figure 6) Attrition curve of fresh $\mathrm{C} 4 \mathrm{Z}-950(\mathrm{O})$ and fresh Grace- $\mathrm{Fe}_{2} \mathrm{O}_{3}(\square)$ particles showing logarithmic attrition behaviour. The attrition rate is initially higher but decreases over time.

Attrition index $A_{i}$ is defined as the slope of the curve for the last 30 min of the test.

Logarithmic attrition behayiour is not necessarily a bad thing and was found to be common especially among fresh samples, whose particles often had small satellites attached to the main particle body. Also spray-dried particles typically contained a smaller or larger number of hollow or doughnut-shaped particles, which are likely to be more prone to attrition than homogenous spheres, see Figure 7. Once such weak particles, satellites and other irregularities have eroded, the remaining material often was found to have high attrition resistance.

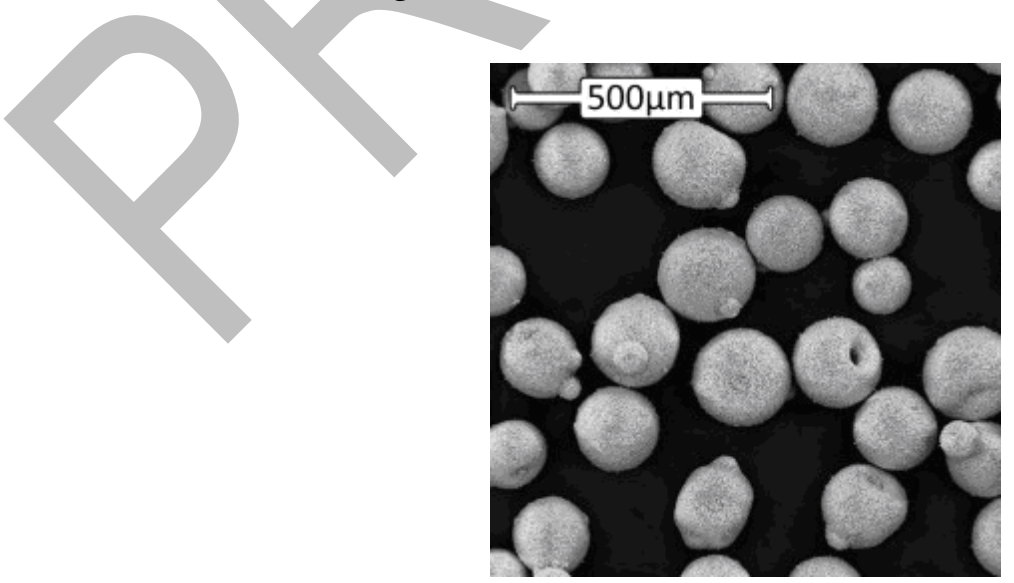

Figure 7) SEM-picture of fresh spray dried oxygen carrier particles. Note that some particles have satellites and that some appears hollow or doughnut-shaped. 
Among the examined samples there were also quite a few made up of soft particles, most often which also had low density. Some such particles appears to have broken down into smaller fragments that were too large to pass the gravitational particle-gas separator, but too small to fall back into the cup. Most of this material was stuck in the settling chamber even as the reactor was disassembled, but could be removed by hitting the device gently with a hammer. Since there was no or little material present in the jet cup during these experiments elutriation of fines ceased completely after a certain time period, see Figure 8.

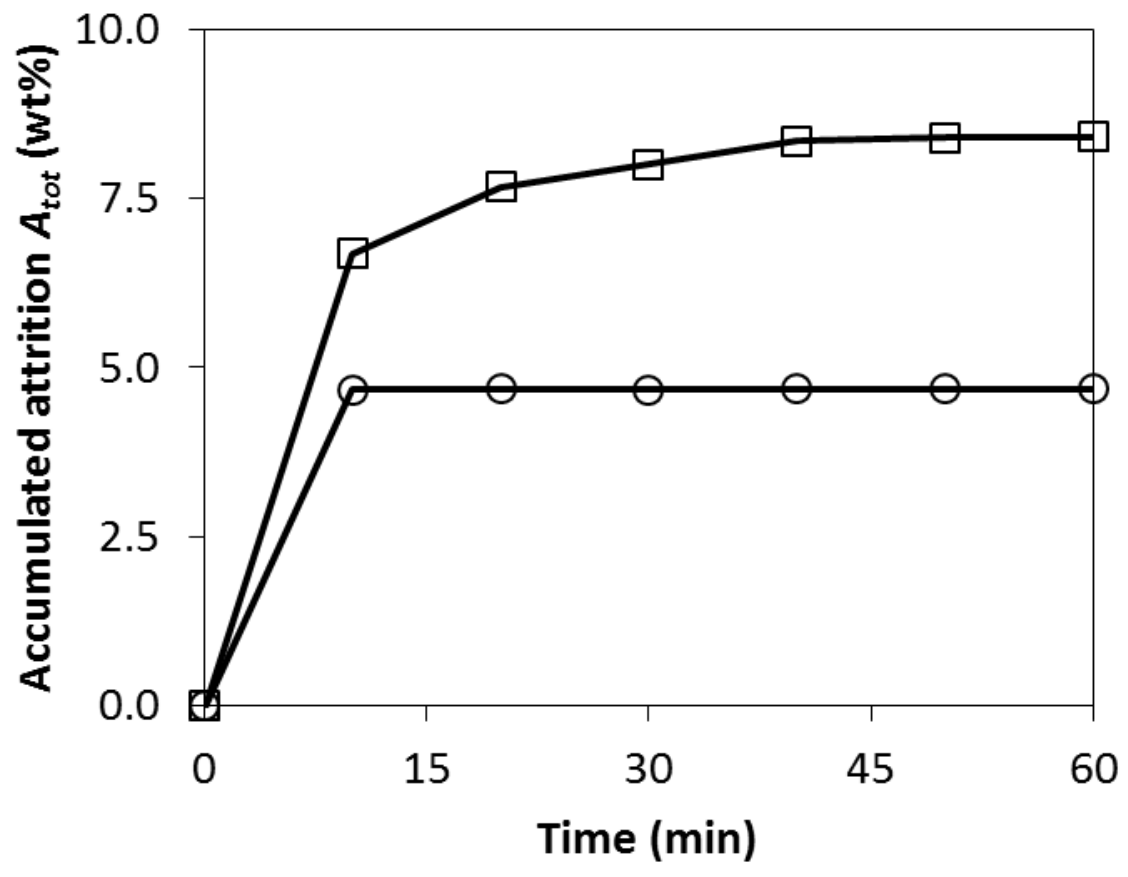

Figure 8) Attrition curve of used M4MZ-1200(०) and used F3-1100(ロ), showing breakage into fragmens too big to pass the gravitational particle-gas separator, but too small to fall back into the jet cup.

Samples with attrition curves like the one in Figures 8 were present mostly as dust when the jet cup was disassembled. Unsurprisingly materials with this kind of behaviour typically had a troubled operational history, as will be further elaborated below.

Due to the different behaviour of different particles it was decided to calculate two numerical indexes to express attrition rate for each material. The first index, $A_{t o t}$, simply describes the total production of fines over the whole test period of $1 \mathrm{~h}$. $A_{t o t}$ is defined in equation (1). The second index $A_{i}$ describes the slope of the attrition curve for the last 30 minutes of the test period and is defined in equation (2). In equations (1-2), $m_{f, t}$ is the weight of the filter at a certain time during the test period and $m_{s}$ is the initial weight of the particle sample.

$$
\begin{array}{ll}
A_{t o t}=100 \times\left(m_{f, t=60 \min }-m_{f, t=0}\right) / m_{s} & (w t \%) \\
A_{i}=100 \times(60 / 30) \times\left(m_{f, t=60 \min }-m_{f, t=30 \min }\right) / m_{s} & (w t \% / h)
\end{array}
$$


$A_{\text {tot }}$ and $A_{i}$ basically provide attrition rates expressed as wt $\%$ fines caught in the filter for a certain time period. High values imply poor resistance to attrition. For particles with perfect linear attrition, $A_{t o t}$ and $A_{i}$ should be exactly the same since the test period is one hour. For particles with logarithmic attrition $A_{i}$ might provide a fairer indication of long term stability since satellites and weak particles are likely to have been eroded during the initial 30 min test period. For particles behaving as in Figure 8 no numbers are provided for $A_{i}$, since those would vastly overrate the attrition resistance of those materials. See section 5 for further comments.

It is important to point out that $A_{t o t}$ and $A_{i}$ are products of a specific testing procedure so they should not be interpreted as the expected lifetime of oxygen carrier particles in a realworld chemical looping combustor. In fact, $A_{t o t}$ and $A_{i}$ could be expected to describe greatly accelerated mechanical attrition compared to what could be expected in an actual reactor due to the very harsh conditions in the jet cup. This can be exemplified by the expected life time of $\mathrm{N}-\mathrm{Vito} / \mathrm{N}-\mathrm{Vito}-\mathrm{Mg}$ particles which was estimated to $33000 \mathrm{~h}$ during extensive testing in a $10 \mathrm{~kW}_{\text {th }}$ chemical looping combustor ${ }^{25}$, while $A_{i}$ measured with the jet cup indicates a lifetime of only $1250 \mathrm{~h}$.

\section{Results}

\subsection{Attrition resistance}

The results of the experiments conducted can be found in Table 5. In addition to measured attrition index, the attrition behaviour (linear, logarithmic) of each sample is reported. All materials have also been assigned to one of four groups (A-D) based on their performance, with respect to attrition during continuous chemical looping combustion experiments. The following criteria were used when putting each material into a certain group:

A. Materials which have been successfully operated in $10 \mathrm{~kW}_{\text {th }}$ reactor with low attrition. The generation of fines was in all cases between 0.02-0.002 $\mathrm{wt} \% / \mathrm{h}$, if defined as the amount of elutriated particles smaller than $45 \mu \mathrm{m}$. This reactor type involves riser gas velocities of about $3 \mathrm{~m} / \mathrm{s}$, cyclone inlet velocities around $8 \mathrm{~m} / \mathrm{s}$, and nozzle outlet velocities around $20 \mathrm{~m} / \mathrm{s}$, i.e. conditions comparable to large-scale applications. So group A materials would likely be feasible for real-world applications.

B. Materials which have been successfully operated in $300 \mathrm{~W}_{\text {th }}$ reactor with low attrition. The generation of fines for these materials was below $0.05 \mathrm{wt} \% / \mathrm{h}$, if defined as the amount of elutriated particles smaller than $45 \mu \mathrm{m}$ plus the amount of such fine particles present in the inventory. This reactor type operates without cyclone and grid jets and all gas velocities are below $1 \mathrm{~m} / \mathrm{s}$. Group B materials could be feasible for practical applications but needs to be further evaluated at harsher conditions.

C. Materials which have been successfully operated in $300 \mathrm{~W}_{\text {th }}$ reactor, but with more significant attrition compared to group B. For these materials the generation of fines was in the range $0.05-0.5 \mathrm{wt} \% / \mathrm{h}$.

D. Materials which have experienced very significant attrition during operation. For these materials the formation of fines was greater than $0.5 \mathrm{wt} \% / \mathrm{h}$. 


\begin{tabular}{|c|c|c|c|c|c|}
\hline Oxygen carrier & Group & & $A_{\text {tot }}(w t \%)$ & $A_{i}(w t \% / h)$ & Behaviour \\
\hline \multirow[t]{2}{*}{ N-Vito } & $A$ & fresh & 0.70 & 0.48 & logarithmic \\
\hline & & used $^{\S}$ & 0.08 & 0.08 & linear \\
\hline \multirow[t]{2}{*}{$\mathrm{N}-$ Vito-Mg } & $A$ & fresh & 0.95 & 0.64 & logarithmic \\
\hline & & used $^{\S}$ & 0.08 & 0.08 & linear \\
\hline \multirow[t]{2}{*}{ Grace- $\mathrm{Fe}_{2} \mathrm{O}_{3}$} & $A$ & $\operatorname{fresh}^{\S \S}$ & 2.23 & 1.28 & logarithmic \\
\hline & & used & 0.32 & 0.12 & logarithmic \\
\hline \multirow[t]{2}{*}{ N-IFP } & $A$ & fresh & 0.58 & 0.16 & logarithmic \\
\hline & & used & 0.16 & 0.16 & linear \\
\hline \multirow[t]{2}{*}{$\mathrm{CaMn}_{0.9} \mathrm{Mg}_{0.1} \mathrm{O}_{3-\delta}$} & $A$ & fresh & 1.03 & 0.60 & logarithmic \\
\hline & & used & 0.38 & 0.32 & $\approx$ linear \\
\hline \multirow[t]{2}{*}{ Grace-NiO } & $A$ & fresh & - & - & unavailable \\
\hline & & used & 0.61 & 0.57 & zlinear \\
\hline \multirow[t]{2}{*}{ N2AM-1400 } & $B$ & fresh & 0.22 & 0.16 & logarithmic \\
\hline & & used & 0.12 & 0.12 & linear \\
\hline \multirow[t]{2}{*}{ F6AM-1150 } & $B$ & fresh & 10.95 & 9.65 & $\approx$ linear \\
\hline & & used & 0.52 & 0.40 & zlinear \\
\hline \multirow{2}{*}{$\mathrm{N} 18-\alpha-\mathrm{Al}_{2} \mathrm{O}_{3}$} & $B$ & fresh & 2.96 & 1.44 & logarithmic \\
\hline & & used $^{\S \S}$ & 0.50 & 0.52 & linear \\
\hline \multirow[t]{2}{*}{$\mathrm{N} 21-\gamma-\mathrm{Al}_{2} \mathrm{O}_{3}$} & $B$ & $\operatorname{fresh}^{\S \S}$ & 3.16 & 2.61 & logarithmic \\
\hline & & used $^{\S \S}$ & 0.54 & & linear \\
\hline \multirow[t]{2}{*}{ F6A-1100 } & $B$ & fresh & 8.41 & 7.25 & zlinear \\
\hline & & used & 2.67 & 2.67 & linear \\
\hline \multirow[t]{2}{*}{ Ilmenite } & $B$ & fresh & 0.75 & 0.46 & logarithmic \\
\hline & & used $^{\S \S}$ & 6.56 & 5.68 & $\approx$ linear \\
\hline $\mathrm{CaMn}_{0.875} \mathrm{Ti}_{0.125} \mathrm{O}_{3}$ & $B$ & $\begin{array}{l}\text { fresh }^{\$ s} \\
\text { used }\end{array}$ & $\begin{array}{l}20.12 \\
8.63\end{array}$ & $\begin{array}{l}8.52 \\
6.72\end{array}$ & $\begin{array}{l}\text { logarithmic } \\
\text { चlinear }\end{array}$ \\
\hline \multirow[t]{2}{*}{ Iron oxide scales } & $C$ & $\operatorname{fresh}^{\S \S}$ & 1.66 & 1.48 & $\approx$ linear \\
\hline & & & 0.99 & 0.83 & $\approx$ linear \\
\hline \multirow[t]{2}{*}{ N4MZ-1400 } & $C$ & fresh & 21.91 & 18.97 & logarithmic \\
\hline & & & 13.90 & 10.60 & logarithmic \\
\hline \multirow[t]{2}{*}{ C2Z-1050 } & & & 19.50 & 20.22 & linear \\
\hline & & used & 27.12 & 27.22 & linear \\
\hline \multirow[t]{2}{*}{ M4MZ-1200 } & $C$ & fresh & 3.22 & 3.26 & linear \\
\hline & & used & $4.69^{\S \S \delta}$ & & destroyed \\
\hline \multirow[t]{2}{*}{ M4MZ-1150 } & & fresh & $41.02^{\S \S \S}$ & & destroyed \\
\hline & & used & $4.05^{\S \S \S}$ & & destroyed \\
\hline \multirow{2}{*}{ Manganese ore ${ }^{\S \S \S \S}$} & $D$ & fresh & - & - & unavailable \\
\hline & & used & 5.79 & 3.94 & logarithmic \\
\hline \multirow{2}{*}{ Manganese ore ${ }^{\S \S \$ \& \delta}$} & $D$ & fresh & 5.08 & 2.01 & logarithmic \\
\hline & & used & 6.16 & 3.01 & logarithmic \\
\hline \multirow[t]{4}{*}{ C4Z-950 } & $D$ & fresh & 5.96 & 3.47 & logarithmic \\
\hline & & used & 7.92 & 6.78 & $\approx$ linear \\
\hline & $D$ & fresh & $16.37^{\S \S \S}$ & & destroyed \\
\hline & & used & $10.36^{\S \S \S}$ & & destroyed \\
\hline & $D$ & fresh & 32.86 & 33.12 & linear \\
\hline 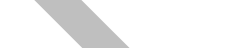 & & used & $8.41^{\S \S \S}$ & & destroyed \\
\hline F7-950 & $D$ & fresh & $18.40^{\S \S \S}$ & & destroyed \\
\hline & & used & $1.47^{\S \S \S}$ & & destroyed \\
\hline F6MZ-1100 & $D$ & fresh & $50.71^{\S \S \S}$ & & destroyed \\
\hline & & used & $23.75^{\S \S \S}$ & & destroyed \\
\hline
\end{tabular}

Table 5. Attrition characteristics of the materials examined in this study. 
The attrition index and crushing strength of each material divided into groups A-D can be found in Figure 9 below. Particles that experienced attrition in accordance with Figure 8 above, and thus were attributed the behaviour "destroyed" in Table 5, have been assigned an $A_{i}$ index of 35 . This was done in order for them to show up in the comparison even though it was not possible to measure a reliable $A_{i}$ for these materials.

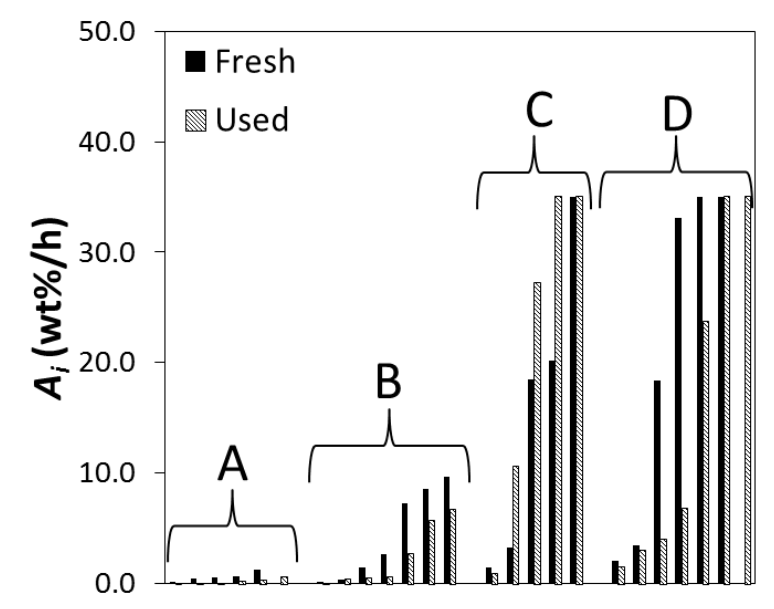

Figure 9a) Attrition index $A_{i}$ of materials divided into groups $A-D$, as per Table 5.

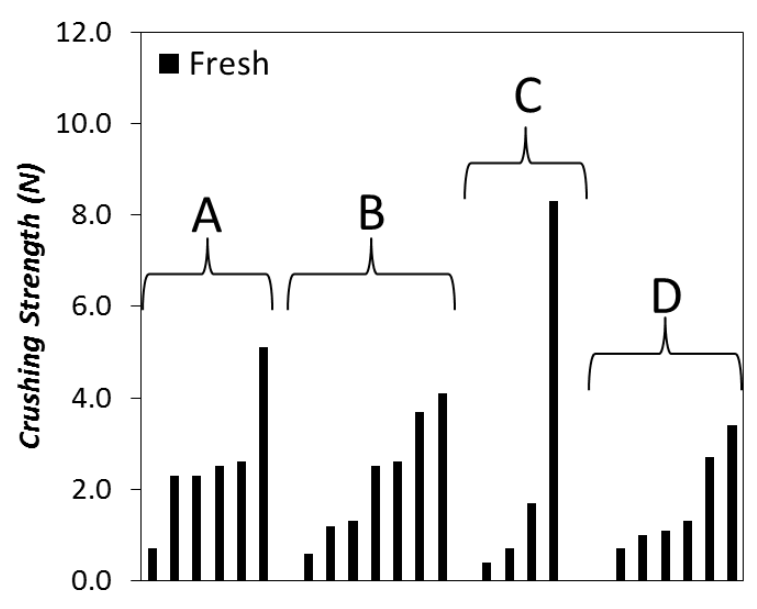

Figure 9b) Crushing strength of materials divided into groups A-D, as per Table 5.

It is evident from Figure 9a that attrition index gives a good indication of whether a certain material is suitable for continuous operation or not. Materials in group A and to some extent also in group B clearly have much lower attrition index compared to most of those in group C and D. This is true not only for used materials but for fresh samples as well.

As for crushing strength of fresh particles the correlation is not as evident in Figure $9 \mathrm{~b}$. Nevertheless there is a certain pattern. Attrition index $A_{i}$ of fresh particles is shown as a function of crushing strength of fresh particles in Figure 10a below, while Figure 10b shows $A_{i}$ of used particles as a function of crushing strength of fresh particles.

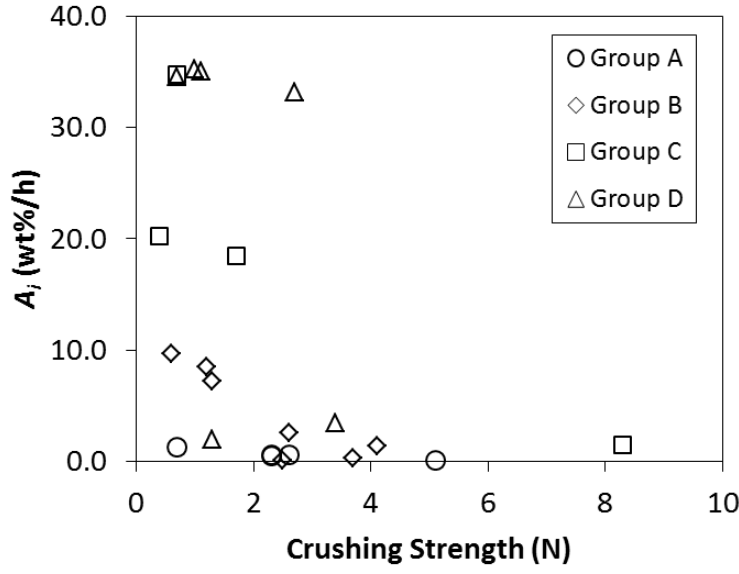

Figure 10a) $A_{i}$ of fresh particles as a function of crushing strength of fresh particles.

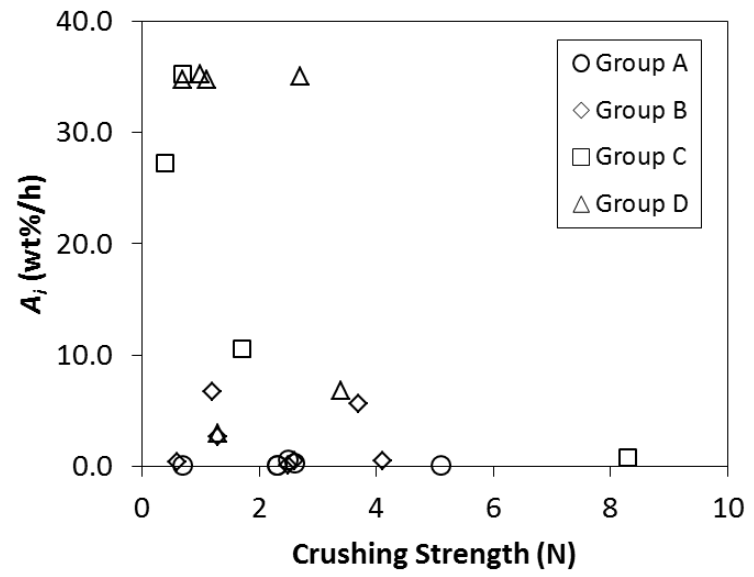

Figure 10b) $A_{i}$ of used particles as a function of crushing strength of fresh particles. 
In Figure 10 it can be seen that there are some correlation between crushing strength and attrition index. A close look at the performance of fresh particles reveal that 9 out of 11 materials with $A_{i}$ below $5 \mathrm{wt} \% / \mathrm{h}$ have a crushing strength above $2 \mathrm{~N}$, whereas 5 out of 6 materials with $A_{i}$ above $20 \mathrm{wt} \% / \mathrm{h}$ have a crushing strength of $1.1 \mathrm{~N}$ or below. Moreover, in the group with crushing strength below $2 \mathrm{~N}$ comprising ten materials there are in fact only two materials with $A_{i}$ below $7 \mathrm{wt} \% / \mathrm{h}$, whereas in the group with crushing strength above $2 \mathrm{~N}$ comprising 12 materials, there is only one material with $A_{i}$ above $7 \mathrm{wt} \% / \mathrm{h}$. Thus, for the here tested particles it is clear that those with a crushing strength above $2 \mathrm{~N}$ were much more likely to show low mechanical attrition compared to softer ones.

It can be concluded that crushing strength, which is a quite simple method to use, may give a valuable first indication of whether a particle has sufficient strength or not. The jet cup method used in this work appears to provide a considerably better picture though. It should be stressed that sustained operation with fuel is necessary to draw safe conclusions, since jet cup tests take place at room temperature and without chemical reactions.

Scrutinizing Tables 3-5, it is possible to draw a few other conclusions as well. One important observation is that there is always a distinct and often very significant difference in resistance to mechanical attrition between fresh and used particles of the same sample. In Figure 11, $\log A_{i}$ of used particles is presented as function of $\log A_{i}$ of fresh particles.

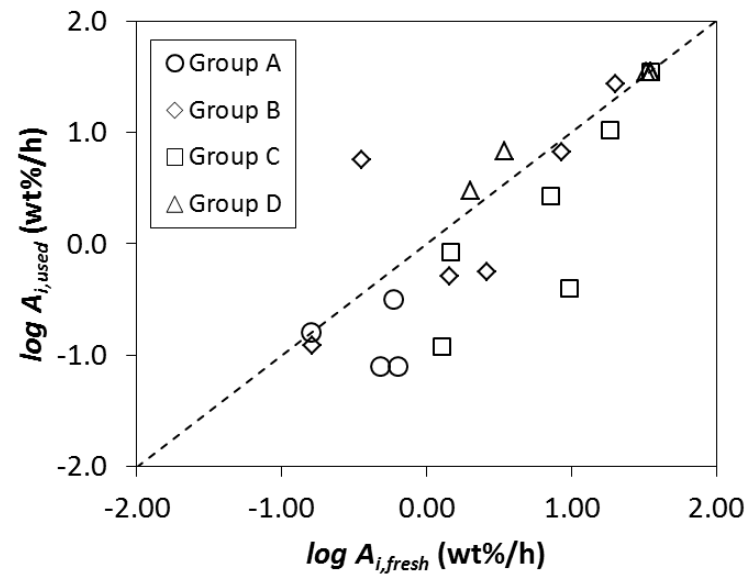

Figure 11) $\log A_{i}$ of used particles as function of $\log A_{i}$ of fresh particles.

In Figure 11, it can be seen that most materials performed significantly better after operation with fuel compared to samples of fresh particles. For some materials, even very soft ones, the improvement was considerable. The most important differing material is ilmenite, for which fresh particles had high crushing strength and performed well in the attrition tests, while used particles showed greatly accelerated attrition behaviour.

This indicates that operation in an actual reactor always results in certain changes to the oxygen carrier. There are many possible mechanisms for such changes. Mechanical milling or grinding of particles into more ideal spheres over time or loss of satellites and weak particles as described in section 3.4 are two options. Thermal sintering due to high temperature and exothermic reactions or stress induced due to chemical reactions are other possibilities. Table 2 provides a number of possible mechanisms which could influence oxygen carrier particles. 
An important implication of this observation is that oxygen carriers manufactured according to the general principles described in Table 3 could hardly be considered as final products. Instead it seems inevitable that practical operation will change the properties of fresh oxygen carrier particles (to a smaller or larger degree), until some kind of steady state condition is reached. One notable consequence is that it seems hard to predict and model the long term performance of different oxygen carrier materials by characterizing fresh or almost fresh particles. In many cases the difference in physical properties and attrition resistance between fresh and used particles is very significant.

It is possible to notice some patterns in Tables 3-5 concerning what kind of materials that performs well. It seems like composite particles with $\mathrm{NiO}$ or $\mathrm{Fe}_{2} \mathrm{O}_{3}$ as active phase and $\mathrm{Al}_{2} \mathrm{O}_{3}$ , $\mathrm{NiAl}_{2} \mathrm{O}_{4^{-}}$or $\mathrm{MgAl}_{2} \mathrm{O}_{4}$-based support always show improved resistance to attrition following operation with fuel. In addition to the mechanical mechanisms suggested above this is likely also an effect of particle densification due to thermal sintering and continuous chemical reactions. If two particles with the same chemical composition are compared, it seems reasonable to believe that the one with higher density (=low porosity) could be expected to be harder and less prone to attrition compared to the one with lower density (=high porosity). The difference in density between fresh and used particles of such samples is often quite large, especially for $\mathrm{Fe}_{2} \mathrm{O}_{3}$-based materials. Used samples of these oxygen carriers also had very high attrition resistance in general.

One interpretation of this observation is that the chemical reaction involved when using these kinds of materials as oxygen carriers does not weaken the particle structure, but enhances it. While there is an obvious risk that particle densification also leads to reduced reactivity due to loss of active surface area, this kind of behaviour may not necessarily be a bad thing. In fact, it is not obyious that highly porous particles with large active surface area are required for chemical looping combustion. For example, the $1016 \mathrm{~h}$ long and highly successful experimental campaign by Linderholm et al. ${ }^{25}$ involved particles with a remarkably low BET surface area of $0.7 \mathrm{~m}^{2} / \mathrm{g}$.

Other materials which show densification and improved attrition resistance for used samples compared to fresh include particles based on the $\mathrm{CaMnO}_{3-\delta}$ perovskite structure. $\mathrm{CaMn}_{0.9} \mathrm{Mg}_{0.1} \mathrm{O}_{3-\delta}$ have been successfully operated in a $10 \mathrm{~kW}_{\text {th }}$ reactor ${ }^{28}$ and showed good attrition resistance, the only manganese-based material examined in this study to do so. It should be noted that these particles were manufactured without support material. Still acceptable attrition resistance was obtained.

Crude particles such as crushed ilmenite and iron oxide scales were found to have decent attrition resistance despite their irregular shape and low sphericity. Ilmenite which had been subject to operation with natural gas experienced swelling and greatly reduced attrition resistance though. The attrition resistances of samples consisting of crushed manganese ore were also relatively low.

All CuO-based materials had low attrition resistance, which in most cases was reduced further by continuous chemical looping combustion, see Table 5. The same is true for all oxygen carriers that used $\mathrm{ZrO}_{2}$ or partially stabilized $\mathrm{Mg}-\mathrm{ZrO}_{2}$ as support material and for combined $\left(\mathrm{Fe}_{\mathrm{x}} \mathrm{Mn}_{1-\mathrm{x}}\right)_{2} \mathrm{O}_{3}$ oxides. Most of these materials were also subject to reduced bulk density following operation with fuel, i.e. particle swelling. One possible explanation could be that continuous phase changes due to chemical reactions in these materials induce stress to the 
stiff particles which leads to formation of cracks and eventually to particle fragmentation. This kind of behaviour is well known for some types of materials, notably for non-stabilized $\mathrm{ZrO}_{2}$, see Chevalier et al. ${ }^{53}$. It should be pointed out that many of these materials had low attrition resistance already as fresh particles, so poor manufacturing procedure or improper calcination conditions should also be considered as possible explanations for the low attrition resistance of these materials.

\subsection{Other observations}

Analysis of the particle size distribution of the samples revealed that many materials with low attrition resistance appear to have eroded via fragmentation. This is illustrated in Figures 12-13 which show the particle size distribution of a poor performing material (F6MZ-1100) and that of a good performing material $\left(\mathrm{CaMn}_{0.9} \mathrm{Mg}_{0.1} \mathrm{O}_{3-\delta}\right)$. Here it shall be pointed out that the size distribution measured through digital image processing as the minimum Feret diameter is somewhat different from what is provided by sieving, and that "s" in Figures 1213 is based on number of particles rather than weight.

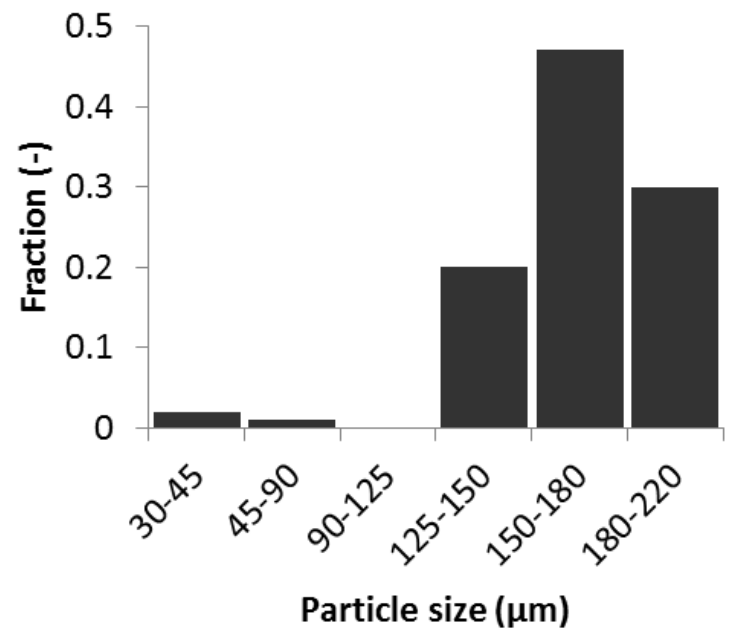

Figure 12a) Particle size distribution of used F6MZ-1100.

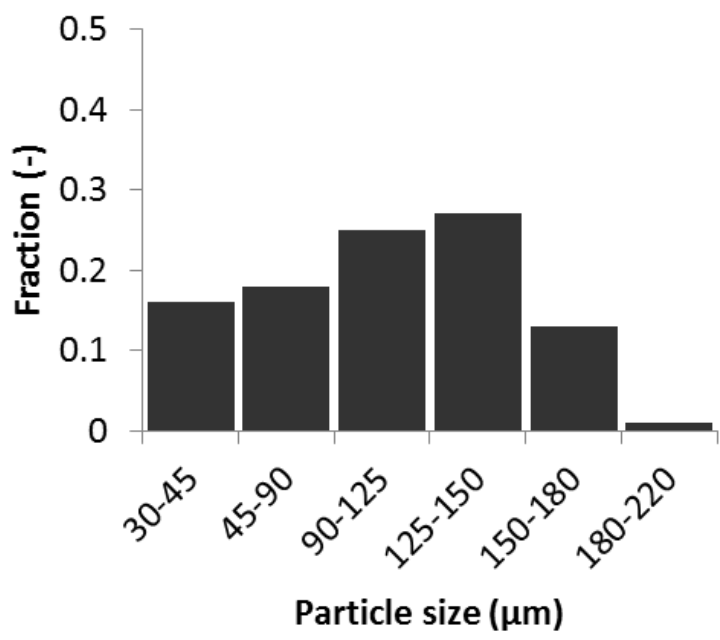

Figure 12b) Particle size distribution of the same material after 1 h attrition test. 


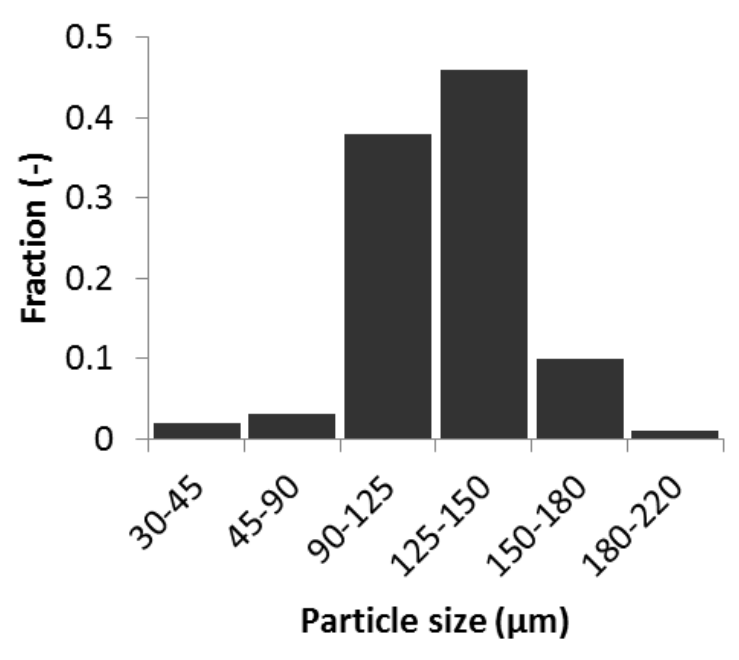

Figure 13a) Particle size distribution of used $\mathrm{CaMn}_{0.9} \mathrm{Mg}_{0.1} \mathrm{O}_{3-\delta}$.

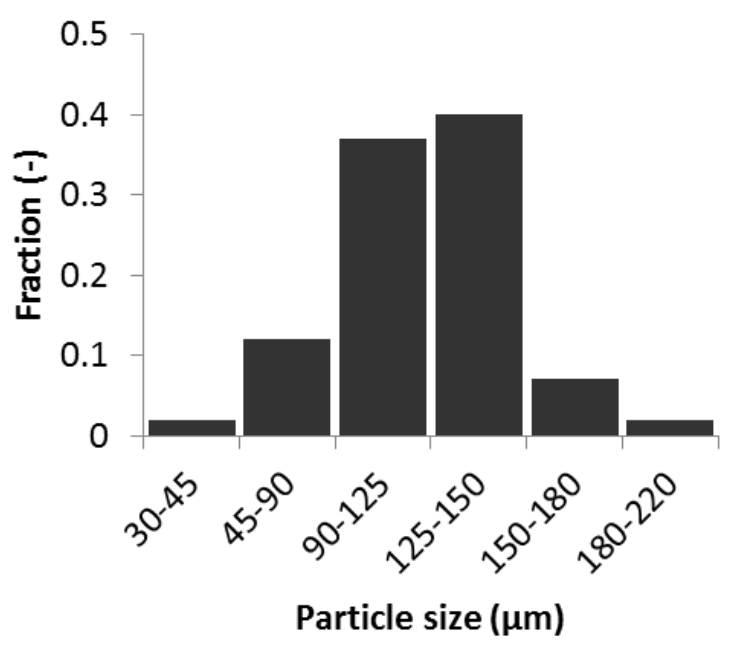

Figure 13b) Particle size distribution of the same material after 1 h attrition test.

From Figure 12-13 it becomes evident that F6MZ-1100 is fractured during attrition testing since there is no other explanation for the presence of material in the size range $90-125 \mu \mathrm{m}$. As comparison, $\mathrm{CaMn}_{0.9} \mathrm{Mg}_{0.1} \mathrm{O}_{3-\delta}$ appears to have maintained its particle size distribution quite well. In this case the average particle size was slightly reduced, likely an effect of abrasion rather than fragmentation.

Light microscope and SEM-pictures of fresh and used particles prior to attrition testing did not enable further conclusions. Comparing SEM-Figures of different particles with similar chemical composition revealed for example that N-IFP had more irregular shape than Grace$\mathrm{NiO}$, see Figure 14. This seems to suggest that N-IFP should be more prone to abrasion than Grace-NiO but measurement with the jet cup suggested higher attrition rate for Grace-NiO. It can be speculated that the higher crushing strength of N-IFP makes up for its irregular shape, but it was not possible to find a general pattern among the examined samples.

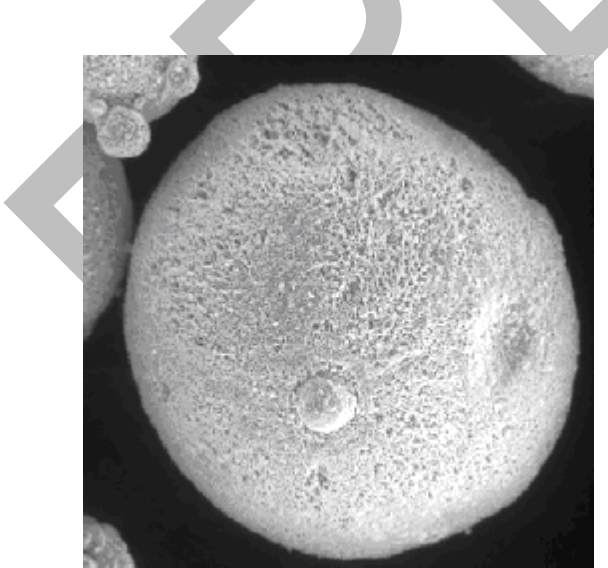

Figure 14a) SEM-picture of Grace-NiO with $d \approx 200 \mu m$.

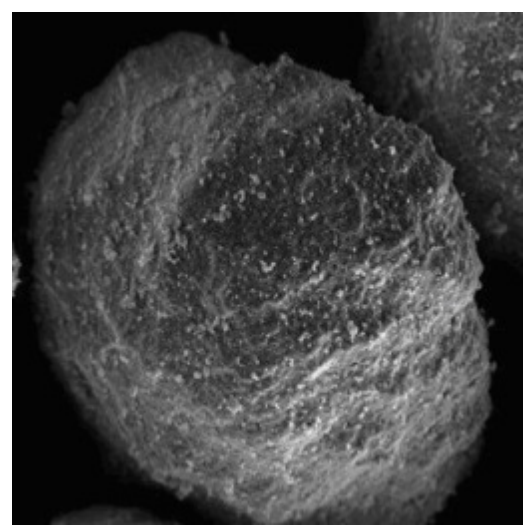

Figure 14b) SEM-picture of N-IFP with $d \approx 200 \mu m$.

\section{Discussion}

The method used to measure attrition of oxygen carrier particles in this article obviously has some limitations. Looking at the potential sources for particle attrition given in Table 2, it 
is evident that it takes at most two mechanisms into account, namely the effects of grid jets and cyclones. Although these are expected to be the largest sources of mechanical attrition in chemical looping combustion, the used methodology is unable to examine for example the effect of elevated temperature or chemical reactions. It should be noted though that it is common practice within the industry to measure attrition resistance of fluidized particles used at hot conditions in cold rigs, as is evident from the ASTM standard for FCC catalysts ${ }^{1}$.

As can be seen in Table 5 the $A_{i}$ index varies greatly between different materials. Would it then be possible to establish an upper limit for acceptable attrition rate? That might be relevant for some applications. But as for chemical looping combustion one should have in mind that this research field is currently wide open. At this point in time it is possible to imagine the use of both expensive materials with long life time and cheap materials with short life time. The choice may very well turn out to be different for different applications. For example, coal combustion most likely requires cheap oxygen carriers that are resistant to sulphur and ash components. Natural gas on the other hand can be cleaned from sulphur and does not contain ash and a high performing but more expensive oxygen carrier could be favourable. Therefore attrition resistance shall be seen as one factor of many when considering the performance of oxygen carrier materials.

While this study indicates a quite robust correlation between crushing strength, jet cup attrition tests and results from actual operation there are also some important deviations. This may be seen as a weakness of the method, but it shall be pointed out that the lack of complete correlation also provides important information about areas where the knowledge needs to be improved. These differences may in fact contribute to improved understanding of the attrition mechanisms, e.g. if a certain type of material performs very well in jet cup attrition testing but very poorly in actual operation this could indicate that chemical reactions or high temperature is of prime importance for such materials.

\section{Conclusions}

A customized jet cup rig for measuring attrition resistance of oxygen carrier particles for chemical looping combustion has been constructed. The rig and methodology have been tested by examining 25 different materials that previously have been subject to continuous chemical looping experiments in reactors at Chalmers University of Technology. Both fresh and used particles have been examined and it is possible to draw a number of conclusions:

- Materials that have performed well during continuous operation at elevated temperature typically also performed well during jet cup tests. It can be concluded that jet cup tests at room temperature does provide a meaningful indication concerning the feasibility of different oxygen carrier materials.

- No strong correlation between the commonly used crushing strength index and attrition resistance measured with the jet cup described in this paper was found. However, it was clear that particles with a crushing strength above $2 \mathrm{~N}$ were more likely to perform well, compared to softer particles.

- As compared to crushing strength, jet cup testing shows a better correlation to performance in actual operation. Thus it should be a significant advantage to include jet cup testing in the early stages of oxygen carrier development, cf. Figure 1. 
- Normally, there is a considerable difference in attrition resistance between fresh and used particles of the same batch. This suggests that continuous oxidation and reduction of particles at high temperature affects the mechanical properties oxygen carriers, and that performing measurements on fresh particles alone not necessarily is sufficient to judge whether a certain particle is suitable for practical applications. The majority of the examined materials performed better after continuous operation with fuel.

- Composite materials with $\mathrm{NiO}$ or $\mathrm{Fe}_{2} \mathrm{O}_{3}$ as active phase and $\mathrm{Al}_{2} \mathrm{O}_{3^{-}}, \mathrm{NiAl}_{2} \mathrm{O}_{4^{-}}$or $\mathrm{MgAl}_{2} \mathrm{O}_{4}$-based supports always experienced improved resistance to attrition following operation with fuel. Used particles of this composition also had very high attrition resistance in general.

- Materials based on the $\mathrm{CaMnO}_{3-\delta}$ perovskite structure also experienced improved resistance to attrition following operation with fuel. Used $\mathrm{CaMn}_{0.9} \mathrm{Mg}_{0.1} \mathrm{O}_{3-\delta}$ particles were found to have high attrition resistance.

- Despite having irregular shape, materials such as ilmenite and iron oxide scales were found to have reasonably high attrition resistance. Ilmenite that had been subject to chemical looping combustion with natural gas fared much worse than fresh ilmenite though.

- Most materials containing smaller or larger amounts of $\mathrm{CuO}$ as active phase or $\mathrm{ZrO}_{2}$ based support experienced reduced attrition resistance during operation. All such materials also had low attrition resistance to begin with. The same was true for $\left(\mathrm{Fe}_{\mathrm{x}} \mathrm{Mn}_{1-\mathrm{x}}\right)_{2} \mathrm{O}_{3}$ combined oxides.

\section{Acknowledgments}

This work was performed with financial support from the European Research Council via the NOCO2 project and the INNOCUOUS project, both parts of the Seventh Framework Programme. The contribution of Adrian Gunnarsson, Simon Lindqvist, Patrik Gyllén, Joakim Hedström, Johan Larsson and Ramyar Baban in the design and construction of the jet cup rig as part of their Bachelor's Thesis work is also acknowledged.

\section{References}

[1] ASTM D5757-95: Standard Test Method for Determination of Attrition and Abrasion of Powdered Catalysts by Air Jets; ASTM: Philadelphia, United States, 1995.

[2] P. Cho, T. Mattisson, A. Lyngfelt, Comparison of iron-, nickel-, copper- and manganesebased oxygen carriers for chemical-looping combustion, Fuel 83 (2004) 1215-1225

[3] T. Mattisson, M. Johansson, A. Lyngfelt, Multi-cycle reduction and oxidation of different types of iron oxide particles - application to chemical-looping combustion, Energy \& Fuels 18 (2004) 628-637.

[4] R. Cocco, Y. Arrington, R. Hays, J. Findlay, S.B.R. Karri, T.M. Knowlton, Jet cup attrition testing, Powder Technology 200 (2010) 224-233.

[5] R. Zhao, J.G. Goodwin, K. Jothimurugesan, J.J. Spivey, S.K. Gangwal, Comparison of attrition test methods: STM standard fluidized bed vs jet cup, Industrial \& Engineering Chemistry Research 39 (2000) 1155-1158. 
[6] S.A. Weeks, P. Dumbill, Method speeds FCC catalyst attrition resistance determination, Oil \& Gas Journal 88 (1990) 38-40.

[7] Carbon dioxide Capture and Storage. Intergovernmental Panel on Climate Change. Cambridge University Press, 2005.

[8] W.K. Lewis, E.R. Gilliland, W.P. Sweeney, Gasification of Carbon Metal Oxides in a Fluidized Powder Bed, Chem. Eng. Prog. 47 (1951) 251-256.

[9] W.K. Lewis, E.R. Gilliland, US Patent 2,665,972, 1954.

[10] H.J. Richter, K. Knoche, Reversibility of combustion processes, ACS symposium series 235 (1983) 71-85.

[11] M. Ishida, D. Zheng, T. Akehata, Evaluation of a chemical-looping combustion powergeneration system by graphic exergy analysis, Energy 12 (1987) 147-154.

[12] M. Ishida, H. Jin, A new advanced power-generation system using chemical-looping combustion, Energy 19 (1994) 415-422.

[13] A. Lyngfelt, B. Leckner, T. Mattisson, A fluidized-bed combustion process with inherent $\mathrm{CO}_{2}$ separation; application of chemical-looping combustion, Chemical Engineering Science 56 (2001) 3101-3113.

[14] A. Lyngfelt, Oxygen Carriers for Chemical Looping Combustion - $4000 \mathrm{~h}$ of Operational Experience, Oil and Gas Science and Technology 66 (2011) 161-172.

[15] J. Adanez, A. Abad, F. Garcia-Labiano, P. Gayán, L.F. De Diego, Progress in chemicallooping combustion and reforming technologies, Progress in Energy and Combustion Science 38 (2012) 215-282.

[16] A. Lyngfelt, Chemical-looping combustion of solid fuels - Status of development, Applied Energy, in press, DOI: 10.1016/j.apenergy.2013.05.043.

[17] L. S. Fan, Chemical looping systems for fossil energy conversion, American Institute of Chemical Engineers and John Wiley \& Sons 2010.

[18] C.R. Bemrose, J. Bridgwater, A review of attrition and attrition test methods, Powder Technology 49 (1987) 97-126.

[19] J. Werther, J. Reppenhagen, Catalyst attrition in fluidized-bed systems, AIChE Journal 45 (1999) 2001-2010.

[20] F. Scala, F. Montagnaro, P. Salatino, Attrition of limestone by impact loading in fluidized beds, Energy \& Fuels 21 (2007) 2566-2572.

[21] F. Scala, P. Salatino, Attrition of limestone by impact loading in fluidized beds: The influence of reaction conditions, Fuel Processing Technology 91 (2007) 1022-1027.

[22] F. Scala, P. Salatino, R. Boerefijn, M. Ghadiri, Attrition of sorbents during fluidized bed calcination and sulphation, Powder Technology 107 (2000) 153-167.

[23] F. Scala, A. Cammarota, R. Chirone, P. Salatino, Comminution of limestone during batch fluidized-bed calcination and sulfation, AIChE Journal 43 (1997) 363-373.

[24] F. Scala, P. Salatino, R. Boerefijn, M. Ghadiri, Attrition of sorbents during fluidized bed calcination and sulphation, Powder Technology 107 (2000) 153-167.

[25] R.M. Contractor, D.I. Garnett, H.S. Horowitz, H.E. Bergna, G.S. Patience, J.T. Schwartz, G.M. Sisler, A new commercial scale process for $n$-butane oxidation to maleic anhydride using a circulating fluidized bed reactor. Studies in Surface Science and Catalysis 82 (1994) 233-242. 
[26] R. Boerefijn, N.J. Gudde, M. Ghadiri, A review of attrition of fluid cracking catalyst particles, Advanced Powder Technology 11 (2000) 145-174.

[27] T.A. Brown, F. Scala, S.A. Scott, J.S. Dennis, P. Salatino, The attrition behaviour of oxygen-carriers under inert and reacting conditions, Chemical Engineering Science 71 (2012) 449-467.

[28] P. Gayán, L.F. de Diego, F. Garcia-Labiano, J. Adanez, A. Abad, C. Dueso, Effect of support on reactivity and selectivity of Ni-based oxygen carriers for chemical-looping combustion, Fuel 87 (2008) 2641-2650.

[29] A. Lyngfelt, H. Thunman, Construction and $100 \mathrm{~h}$ of operational experience of a 10-kW chemical looping combustor. Chapter 36 in Carbon Dioxide Capture for Storage in Deep Geologic Formations - Results from the $\mathrm{CO}_{2}$ Capture Project, Volume 1 - Capture and Separation of Carbon Dioxide From Combustion Sources. Ed.: Thomas, D. Elsevier Science, London 2005. pp. 625-646.

[30] C. Linderholm, T. Mattisson, A. Lyngfelt, Long-term integrity testing of spray-dried particles in a $10 \mathrm{~kW}$ chemical-looping combustor using natural gas as fuel, Fuel 88 (2009) 2083-2096.

[31] N. Berguerand, A. Lyngfelt, The use of petroleum coke as fuel in a $10 \mathrm{~kW}_{\text {th }}$ chemicallooping combustor, International Journal of Greenhouse Gas Control 2 (2008) 169-179.

[32] J. Adanez, P. Gayán, J. Celaya, L.F. de Diego, F. Garcia-Labiano, A. Abad, Chemical looping combustion in a $10 \mathrm{~kW}_{\text {th }}$ prototype using a $\mathrm{CuO} / \mathrm{Al}_{2} \mathrm{O}_{3}$ oxygen carrier: Effect of operating conditions on methane combustion, Industrial and Engineering Chemistry Research 45 (2006) 6075-6080.

[33] M. Källén, M. Rydén, C. Dueso, T. Mattisson, A. Lyngfelt, $\mathrm{CaMn}_{0.9} \mathrm{Mg}_{0.1} \mathrm{O}_{3-\delta}$ as Oxygen Carrier in a Gas-Fired $10 \mathrm{~kW}_{\text {th }}$ Chemical-Looping Combustion Unit, Industrial and Engineering Chemistry Research 52 (2013) 6923-6932.

[34] M. Rydén, A. Lyngfelt, T. Mattisson, $\mathrm{CaMn}_{0.875} \mathrm{Ti}_{0.125} \mathrm{O}_{3}$ as oxygen carrier for chemicallooping combustion with oxygen uncoupling (CLOU) - experiments in a continuously operating fluidized bed reactor system, Int. Journal of Greenhouse Gas Control 5 (2011) 356366.

[35] M. Rydén, A. Lyngfelt, T. Mattisson, Combined manganese/iron oxides as oxygen carrier for chemical looping combustion with oxygen uncoupling (CLOU) in a circulating fluidized bed reactor system, Energy Procedia 4 (2011) 341-348.

[36] A. Abad, T. Mattisson, A. Lyngfelt, M. Rydén, Chemical-Looping Combustion in a 300 W Continuously Operating Reactor System Using a Manganese-Based Oxygen Carrier, Fuel 85 (2006) 1174-1185.

[37] P. Moldenhauer, M. Ryden, T. Mattison, A. Lyngfelt, Chemical-Looping Combustion and Chemical-Looping with Oxygen Uncoupling of Kerosene with $\mathrm{Mn}$ - and $\mathrm{Cu}$-based Oxygen Carriers in a Circulating Fluidized Bed 300W Laboratory Reactor, Fuel Processing Technology 104 (2012) 378-389.

[38] A. Abad, T. Mattisson, A. Lyngfelt, M. Johansson, The Use of Iron Oxide as Oxygen Carrier in a Chemical-Looping Reactor, Fuel 86 (2007) 1021-1035.

[39] A. Lyngfelt, B. Kronberger, J. Adanez, J.X. Morin, P. Hurst, The GRACE project. Development of oxygen carrier particles for chemical-looping combustion. Design and 
operation of a $10 \mathrm{~kW}$ chemical-looping combustor. Proceedings of the 7th International Conference on Greenhouse Gas Control Technologies, Vancouver, Canada, September 2004. [40] M. Rydén, M. Arjmand, Continuous hydrogen production via the steam-iron reaction by chemical looping in a circulating fluidized-bed reactor, International Journal of Hydrogen Energy 37 (2012) 4843-4854.

[41] M. Rydén, M. Johansson, E. Cleverstam, A. Lyngfelt, T. Mattisson, Ilmenite with addition of $\mathrm{NiO}$ as oxygen carrier for chemical-looping combustion, Fuel 89 (2010) 35233533.

[42] P. Moldenhauer, M. Rydén, A. Lyngfelt, Testing of minerals and industrial by-products as oxygen carriers for chemical-looping combustion in a circulating fluidized-bed $300 \mathrm{~W}$ laboratory reactor, Fuel 93 (2012) 351-363.

[43] P. Moldenhauer, M. Rydén, A. Lyngfelt, T. Mattisson, The use of ilmenite as oxygen carrier with kerosene in a 300W CLC laboratory reactor with continuous circulation. Applied Energy, in press, DOI: 10.1016/j.apenergy.2013.06.009

[44] C. Linderholm, A. Lyngfelt A, A. Cuadrat, E. Jerndal, Chemical-looping combustion of solid fuels - Operation in a $10 \mathrm{~kW}$ unit with two fuels, above-bed and in-bed fuel feed and two oxygen carriers, manganese ore and ilmenite, Fuel 102 (2012) 808-822.

[45] M. Rydén, M. Johansson, A. Lyngfelt, T. Mattisson, $\mathrm{NiO}$ supported on $\mathrm{Mg}-\mathrm{ZrO} 2$ as oxygen carrier for chemical-looping combustion and chemical-looping reforming, Energy \& Environmental Science 2 (2009) 970-981.

[46] P. Moldenhauer, M. Rydén, T. Mattisson, A. Lyngfelt, Chemical-Looping Combustion and Chemical-Looping Reforming of Kerosene in a Circulating Fluidized-Bed 300W Laboratory Reactor, Int. Journal of Greenhouse Gas Control 9 (2012) 1-9.

[47] M. Rydén, A. Lyngfelt, T. Mattisson, Chemical-looping combustion and chemicallooping reforming in a circulating fluidized-bed reactor using Ni-based oxygen carriers, Energy \& Fuels 22 (2008) 2585-2597.

[48] C. Linderholm, E. Jerndal, T. Mattisson, A. Lyngfelt, Investigation of NiO-based mixed oxides in a 300-W chemical-looping combustor, Chem. Eng. Res. Des 88 (2010) 661-672.

[49] C. Linderholm, A. Abad, T. Mattisson, A. Lyngfelt, 160 hours of chemical-looping combustion in a $10 \mathrm{~kW}$ reactor system with a NiO-based oxygen carrier, International Journal of Greenhouse Gas Control 2 (2008) 520-530.

[50] S. Wang, G. Wang, F. Jiang, M. Luo, H. Li, Chemical looping combustion of coke oven gas by using $\mathrm{Fe}_{2} \mathrm{O}_{3} / \mathrm{CuO}$ with $\mathrm{MgAl}_{2} \mathrm{O}_{4}$ as oxygen carrier, Energy and Environmental Science 3 (2010) 1353-1360.

[51] F. Li, H.R. Kim, D. Sridhar, F. Wang, L. Zeng, J. Chen, L.S. Fan, Syngas chemical looping gasification process: Oxygen carrier particle selection and performance, Energy and Fuels 23 (2009) 4182-4189.

[52] M. Ishida, K. Takeshita, K. Suzuki, T. Ohba, Application of $\mathrm{Fe}_{2} \mathrm{O}_{3}-\mathrm{Al}_{2} \mathrm{O}_{3}$ composite particles as solid looping material of the chemical-loop combustor, Energy and Fuels 19 (2005) 2514-2518.

[53] J. Chevalier, L. Gremillard, A.V. Virkar, D.R. Clarke, The Tetragonal-Monoclinic Transformation in Zirconia: Lessons Learned and Future Trends, Journal of the American Ceramic Society 92 (2009) 1901-1920. 